\title{
Recent Advances in the Innate Immunity of Invertebrate Animals
}

\author{
Sadaaki Iwanaga and Bok Luel Lee ${ }^{\dagger, *}$ \\ The Chemo-Sero-Therapeutic Research Institute, Okubo 1-6-1, Kumamoto 860-8568, and \\ Department of Biology, Kyushu University, Fukuoka 812-8581, Japan \\ College of Pharmacy, Pusan National University, Jang-Jeong Dong, Kum-Jeong Ku, Pusan 609-735, Korea
}

Received 20 January 2005

Invertebrate animals, which lack adaptive immune systems, have developed other systems of biological host defense, so called innate immunity, that respond to common antigens on the cell surfaces of potential pathogens. During the past two decades, the molecular structures and functions of various defense components that participated in innate immune systems have been established in Arthropoda, such as, insects, the horseshoe crab, freshwater crayfish, and the protochordata ascidian. These defense molecules include phenoloxidases, clotting factors, complement factors, lectins, protease inhibitors, antimicrobial peptides, Toll receptors, and other humoral factors found mainly in hemolymph plasma and hemocytes. These components, which together compose the innate immune system, defend invertebrate from invading bacterial, fungal, and viral pathogens. This review describes the present status of our knowledge concerning such defensive molecules in invertebrates.

Keywords: Ascidian, Bombyx mori, Crayfish, Defense molecules, Drosophila, Holotrichia diomphalia, Horseshoe crab, Innate immunity, Invertebrate animals, Manduca, Sarcophaga, Tenebrio

\section{Introduction}

The innate immune system is the first line of inducible host defense against bacterial, fungal, and viral pathogens (Hoebe $e t$

\footnotetext{
Abbreviations: lipopolysaccharides, LPS; peptidoglycan, PGN; Creactive proteins, CRPs; Limulus intracellular coagulation inhibitors, LICI; prophenoloxidase, pro-PO; PGN recognition protein-LC, PGRP-LC; immune deficiency, IMD.
}

*To whom correspondence should be addressed. Tel: 82-51-510-2809; Fax: 82-51-513-2801

E-mail: brlee@pusan.ac.kr $a l ., 2004)$. This defense system is essential for the survival and perpetuation of all multicellular organisms (Hoffmann et al., 1999; Salzet 2001). Invertebrates, which do not possess immunoglobulins, have developed unique modalities to detect and respond to microbial surface antigens like lipopolysaccharides (LPS), lipoteichoic acids, lipoproteins, peptidoglycan $(\mathrm{PGN})$ and $(1 \rightarrow 3) \beta$-D-glucans (Begum et al., 2000). Because both invertebrates and vertebrates respond to these substances, it is likely that a system recognizing these epitopes emerged at an early stage in the evolution of animals (Medzhitov and Janeway, 2000; Aderem and Ulevitch, 2000). Moreover, it is well known that various microbial cell wall components elicit a variety of responses that depend on species and cell type (Hoffmann et al., 1999; Cooper et al., 2002). Table 1 summarizes the major biological host defense systems of invertebrates; such systems are also found in mammals (Aderem and Ulevitch, 2000). In invertebrates, toll-like receptor-mediated antimicrobial peptide production (Lemaitre et al., 1996; Imuler and Hoffmann, 2000; Krutzik et al., 2001; Underkill and Orinsky, 2002), hemolymph coagulation (Iwanaga et al., 1978), melanin formation (Sugumaran, 2002), and lectin-mediated complement activation (Fujita, 2002) are prominent immune responses. In addition to these enzyme cascades, a variety of agglutinin-lectins and reactive oxygenproducing and phagocytic systems cooperate with immune reactions to kill invading pathogens (Bogdan et al., 2000). Figure 1 shows the principal defense systems associated with phagocytosis. Invaders detected by these systems are ultimately

Table 1. Major host defense systems in invertebrate animal

1. Hemolymph coagulation system

2. Pro-phenoloxidase (pro-PO) activating system

3. Lectin-complement system

4. Agglutinin-lectin system

5. Antibacterial, antifungal, and antiviral systems mediated by Toll-like receptors and peptidoglycan binding protein (PGBP)

6. Reactive oxygen-producing system

7. Phagocytic system 


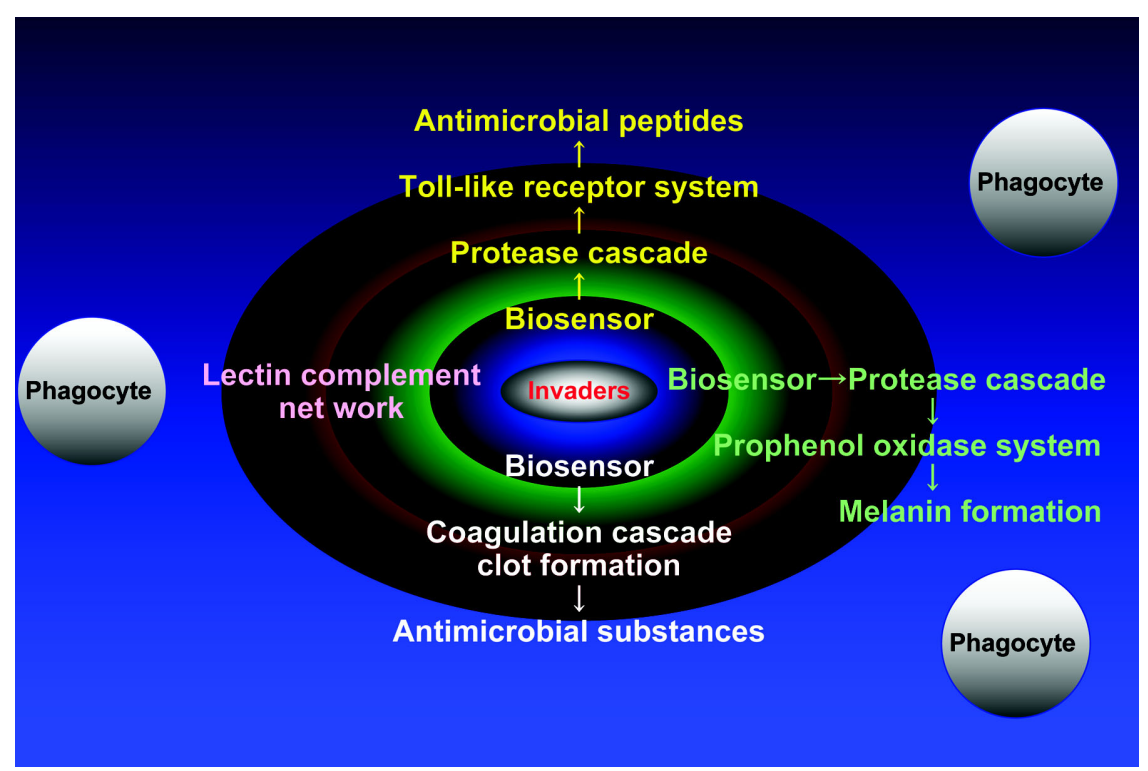

Fig. 1. The principal host defense systems associated with phagocytosis in invertebrates. The major innate immune systems include; hemolymph coagulation, melanization mediated by phenoloxidase, the expression of antimicrobial peptides mediated by Toll-like receptors and the immuno deficiency (IMD) pathway, and the lectin/complement pathway mediated by bacterial cell wall components. Invaders detected by these systems are ultimately engulfed by phagocytic cells, such as macrophage-like, neutrophil-like, or dendrotic cells, and then internalized, processed, and killed. Please refer to the following recent reviews for more information about these systems: Muta and Iwanaga, 1996, 1998; Inamori et al., 2004; Hoffmann et al, 1999, Cerenins and Söderhäll, 2002; Fujita, 2002; Azumi, et al., 2003; Greenberg and Grinstein, 2002; Theopold et al., 2002, 2004; Kim et al., 2002; Iwasaki and Medzhitov, 2004; Hultmark, 2003; Ashida and Brey, 1998; Kanost et al., 2004; Natori, et al., 1999; Nonaka, 2001; Nellaiappan and Sugumaran, 1996; Cooper et al., 2002.

engulfed by phagocytes, such as macrophage-like, neutrophillike and dendritic cells, and are then internalized as phagosomes and finally killed (Greenberg and Grinstein, 2002).

Here, we focus on the present status of innate immunity in invertebrates, with an emphasis on the structures and functions of the defense molecules found the following; the horseshoe crab, the freshwater crayfish, ascidians, and insects including Drosophila melanogaster, Sarcophaga peregrina, Bombyx mori, Manduca sexta, Holotrichia diomphalia and Tenebrio molitor (Fig. 2).

\section{Horseshoe crab (Tachypleus (T) tridentatus)}

Hemolymph and circulating hemocytes The invertebrate Tachypleus tridentatus (Japanese horseshoe crab) (Fig. 2A) is an arthropod, and relies completely on innate immunity, by employing unique and highly efficient host defense systems (Iwanaga et al., 1992). The hemolymph plasma of this animal contains many soluble defense molecules, such as hemocyanins, various lectins, and $\mathrm{C}$-reactive proteins, and thioester bond containing proteins ( $\alpha_{2}$-macroglobulins), in addition to a large numbers of granular hemocytes (amebocytes), which undergo a rapid degranulation on contact with pathogens (Iwanaga et al., 1998). Hemocytes, which compose more than $99 \%$ of circulating cells, contain a variety of defense molecules, which are located in two types of secretary granules large (L)-and small
(S)-granules (Fig. 3) (Muta and Iwanaga, 1996; Iwanaga and Kawabata, 1998). L-granules selectively store more than 25 defense components with molecular masses between 8 and $120 \mathrm{kDa}$. These include clotting factors, a clottable protein coagulogen, proteinase inhibitors, lectins, and antimicrobial proteins. In contrast, the S-granules contain at least six antimicrobial peptides and several proteins of molecular mass $<30 \mathrm{kDa}$. These peptides include large amounts of hairpin-like tachyplesin (17-18 amino acid residues, >10 mg per individual), tachystatins (41-44 residues), tachycitins ( 73 residues) and big defensins (79 residues), which are highly active against Gram-negative and -positive bacteria and fungi (Iwanaga et al., 1994; Iwanaga, 2002).

Table 2 summarizes the various proteins and peptides identified to date in $T$. tridentatus hemocytes and hemolymph plasma. Compared with mammalian blood the hemolymph plasma of Tachypleus tridentatus contains relatively few protein types ( >300 different proteins are present in human plasma), and instead contains three predominant protein types, namely, hemocyanin $\left(\mathrm{O}_{2}\right.$ transporter), C-reactive proteins (CRP) (Iwaki et al., 1999), and $\alpha_{2}$-macroglobulins (Iwaki et al., 1996; Armstrong, 2001; Husted et al., 2002). Moreover, circulating hemocytes are extremely sensitive to bacterial LPS, and respond by degranulating a number of granular components after LPS-mediated stimulation, which results in the formation of hemolymph clot. This rapid clotting response is believed to be important for the animal's host defense, which involves 
A

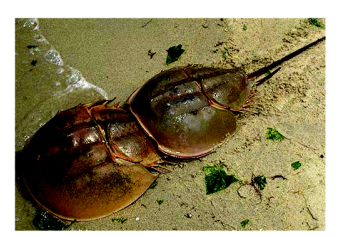

$\mathbf{E}$

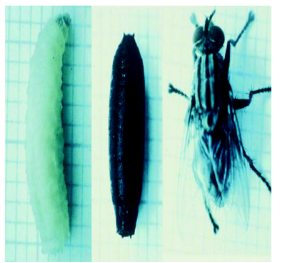

B

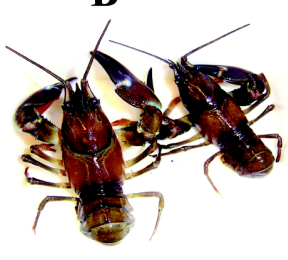

F

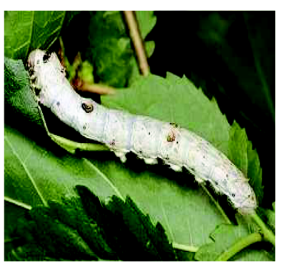

C

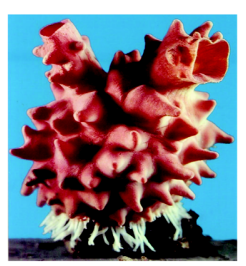

$\mathbf{G}$

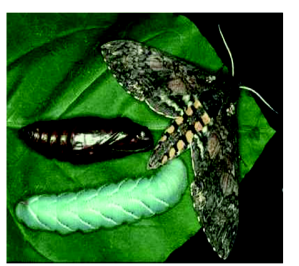

D

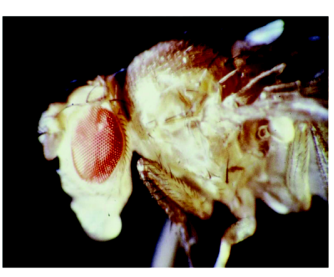

H-1

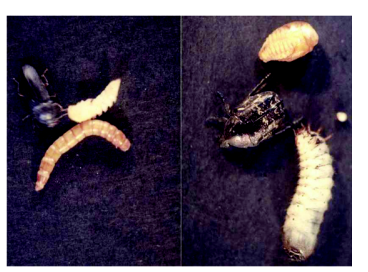

Fig. 2. Mating Japanese horseshoe crabs (Tachypleus tridentatus) (A), the freshwater crayfish (Pacifastacus leniusculus) (B), the sonitary ascidian (Halocynthia roretzi) (C), Drosophila (D), Salcophaga (E), Bombyx mori (F), Manduca sexta (G), Tenebrio molitor (H-1) and Holotrichia diomphalia (H-2).

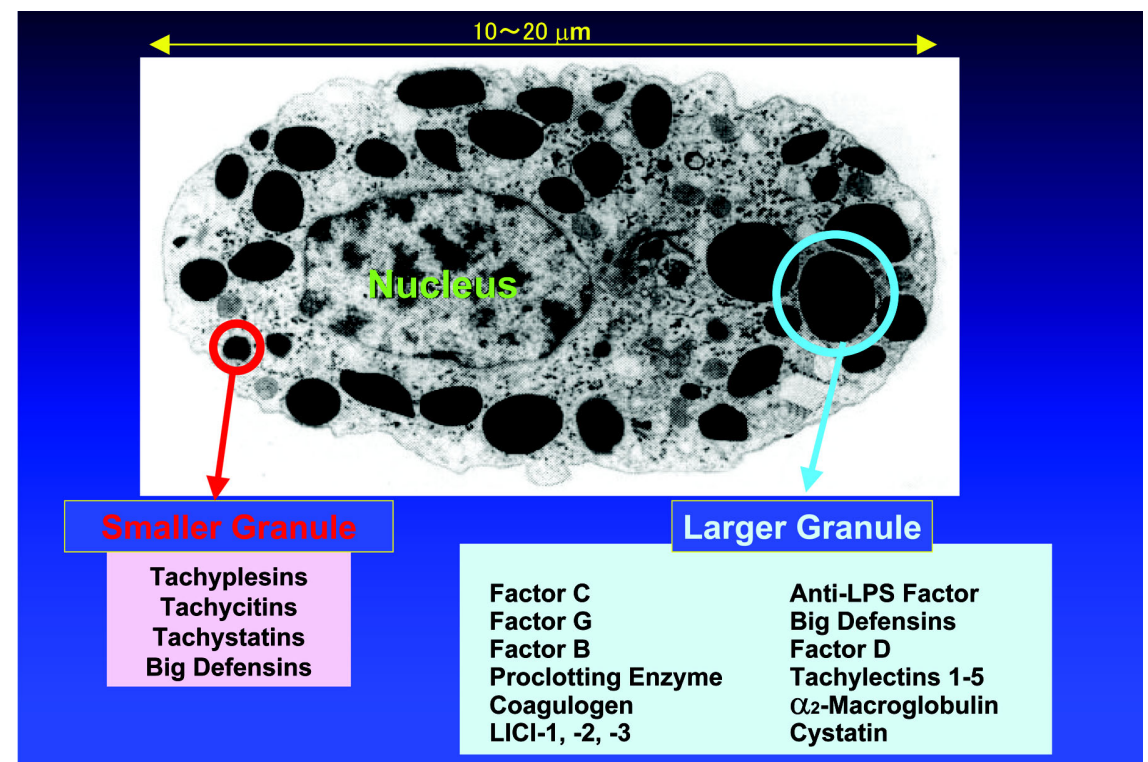

Fig. 3. Electron micrograph of horseshoe crab (T. tridentatus) hemocytes, and major defense molecules that have been identified in large and small cell granules.

engulfing of invading microbes, and in addition prevents hemolymph leakage (Muta and Iwanaga, 1996).

Hemolymph clotting system The hemolymph-clotting phenomenon was first identified as a prominent defense system in the horseshoe crab (Limulus polyphemus) by Bang (Bang, 1956). When Gram-negative bacteria invade the hemolymph, hemocytes detect LPS molecules on their surfaces (Ariki et al., 2004), and then release, via rapid exocytosis, the contents of L- and S-granules (Iwanaga, 1993a,b). These released granular components include two biosensors, named factors $\mathrm{C}$ and $\mathrm{G}$ (Table 2). These two factors are serine protease zymogens and are autocatalytically activated by LPS or $(1 \rightarrow 3)-\beta$-D-glucan, which are major components of the cell walls of Gram-negative bacteria and fungi, respectively. In 1996, Tamura et al. reported that hemocytes contain a $(1 \rightarrow 3)-\beta-D-G l u c a n$ binding protein, which differs from factor $G$ as it does not participate in the hemolymph clotting cascade. One of the authors of this review has previously described in detail LPS and $(1 \rightarrow 3)-\beta$ D-glucan-mediated clotting cascades and their molecular structures, and the functions of the five clotting factors (Table 2), factor $\mathrm{C}$, factor $\mathrm{G}$, factor $\mathrm{B}$, proclotting enzyme, and clottable coagulogen, which all participate in clotting cascades 
Table 2. Defense molecules found in hemocytes and hemolymph plasma of the horseshoe crab

\begin{tabular}{|c|c|c|c|}
\hline Proteins and peptides & Mass (kDa) & Function/specificity & Localization \\
\hline \multicolumn{4}{|l|}{ Coagulation factors } \\
\hline Factor $\mathrm{C}$ & 123 & Serine protease & L-granule \\
\hline Factor B & 64 & Serine protease & L-granule \\
\hline Factor $\mathrm{G}$ & 110 & Serine protease & L-granule \\
\hline Proclotting enzyme & 54 & Serine protease & L-granule \\
\hline Coagulogen & 20 & Gelation & L-granule \\
\hline \multicolumn{4}{|l|}{ Protease inhibitors } \\
\hline LICI-1 & 48 & Serpin/factor C & L-granule \\
\hline LICI-2 & 42 & Serpin/clotting enzyme & L-granule \\
\hline LICI-3 & 53 & Serpin/factor $\mathrm{G}$ & L-granule \\
\hline Trypsin inhibitor & 6.8 & Kunitz-type & ND \\
\hline LTI & 16 & New type & ND \\
\hline LEBP-PI & 12 & New type & L-granule \\
\hline Limulus cystatin & 12.6 & Cystatin family 2 & L-granule \\
\hline$\alpha_{2}$-Macroglobulin & 180 & Complement & Plasma \& L-granule \\
\hline Chymotrypsin inhibitor & 10 & ND & Plasma \\
\hline \multicolumn{4}{|l|}{ Antimicrobial substances } \\
\hline Anti-LPS factor & 12 & GNB & L-granule \\
\hline Tachyplesins & 2.3 & GNB, GPB, FN & S-granule \\
\hline Polyphemusins & 2.3 & GNB, GPB, FN & S-granule \\
\hline Big defensin & 8.6 & GNB, GPB, FN & L \& S-granule \\
\hline Tachycitin & 8.3 & GNB, GPB, FN & S-granule \\
\hline Tachystatins & 6.5 & GNB, GPB, FN & S-granule \\
\hline Factor D & 42 & GNB & L-granule \\
\hline \multicolumn{4}{|l|}{ Lectins } \\
\hline Tachylectin-1 & 27 & LPS (KDO), LTA & L-granule \\
\hline Tachylectin-2 & 27 & GlcNAc, LTA & L-granule \\
\hline Tachylectin-3 & 15 & LPS (O-antigen) & L-granule \\
\hline Tachylectin-4 & 470 & LPS (O-antigen), LTA & ND \\
\hline Tachylectin-5 & $380-440$ & $N$-acetyl group & Plasma \\
\hline Limunectin & 54 & $\mathrm{PC}$ & L-granule \\
\hline $18 \mathrm{~K}-\mathrm{LAF}$ & 18 & Hemocyte aggregation & L-granule \\
\hline Limulin & 300 & HLA/PC, PE, SA, KDO & Plasma \\
\hline LCRP & 300 & $\mathrm{PC}, \mathrm{PE}$ & Plasma \\
\hline TCRP-1 & 300 & $\mathrm{PE}$ & Plasma \\
\hline TCRP-2 & 330 & HLA/PE, SA & Plasma \\
\hline TCRP-3 & 340 & HLA/SA, KDO & Plasma \\
\hline Polyphemin & ND & LTA, GlcNAc & Plasma \\
\hline TTA & ND & SA, GlcNAc, GalNAc & Plasma \\
\hline Liphemin & $400-500$ & SA & Hemolymph \\
\hline Carcinoscorpin & 420 & SA, KDO & Hemolymph \\
\hline GBP & 40 & $\mathrm{Gal}$ & Hemolymph \\
\hline PAP & 40 & Protein A & Hemolymph \\
\hline$(1 \rightarrow 3) \beta$-D-glucan binding protein & 168 & Pachyman, cardlan & Hemocyte \\
\hline \multicolumn{4}{|l|}{ Others } \\
\hline Transglutaminase (TGase) & 86 & Cross-linking & Cytosol \\
\hline $8.6 \mathrm{kDa}$ protein & 8.6 & TGase substrate & L-granule \\
\hline Pro-rich proteins (Proxins) & 80 & TGase substrate & L-granule \\
\hline Limulus kexin & 70 & Precursor processing & ND \\
\hline Hemocyanin & 3600 & $\mathrm{O}_{2}$ transporter (PO activity) & Plasma \\
\hline Toll-like receptor (tToll) & 110 & ND & Hemocyte \\
\hline L1 & 11 & Unknown & L-granule \\
\hline L4 & 11 & Unknown & L-granule \\
\hline
\end{tabular}

LICI, Limulus intracellular coagulation inhibitor; LTI, Limulus trypsin inhibitor; LEBP-PI, Limulus endotoxin-binding protein-protease inhibitor; GNB, Gram-negative bacteria; GPB, Gram-positive bacteria; FN, fungus; LPS, lipopolysaccharide; LAF, Limulus 18-kDa agglutination-aggregation factor; KDO, 2-keto-3-deoxyoctonic acid; PC, phosphorylcholine; PE, phosphorylethanolamine; SA, sialic acid; TTA, Tachypleus tridentatus agglutinin; LCRP, Limulus C-reactive protein; TCRP, Tachypleus C-reactive protein; HLA, hemolytic activity; LTA, lipoteichoic acid; GBP, galactose-binding protein; PAP, protein A binding protein; PO, phenoloxidase; ND, not determined. 
(Iwanaga et al., 1992; Iwanaga 1993a,b; Muta and Iwanaga 1996a,b). Therefore, we will only provide an outline of the clotting cascades here. Figure 4 illustrates the LPS and $(1 \rightarrow 3)-\beta$-D-glucan-mediated clotting cascades of the hemolymph of T. tridentatus (Iwanaga et al., 1994), and includes limulus intracellular coagulation inhibitors (LICI), which act as regulators of the cascade reaction (Agarwara $e t$ al., 1996). These clotting cascades both involve four serine protease zymogens, factors C $(123 \mathrm{kDa}), \mathrm{B}(64 \mathrm{kDa}), \mathrm{G}$ $(110 \mathrm{kDa})$, proclotting enzyme $(54 \mathrm{kDa})$, and coagulogen (20 kDa) (Bergner et al., 1996, 1997). In the presence of LPS or synthetic lipid A analogs, factor C is autocatalytically activated to an active form, factor C (Iwanaga et al., 1992; Tan et al., 2000). Factor B zymogen is then activated by factor $\mathrm{C}$ to its active form (factor $\mathrm{B}$ ), which activates proclotting enzyme to clotting enzyme. Clotting enzyme then converts coagulogen to an insoluble coagulin gel, which is composed of non-covalent homopolymers, through head to tail interaction (Kawasaki et al., 2000). On the other hand, factor $\mathrm{G}$ zymogen consisting of two heterosubunits and is autocatalytically activated in the presence of $(1 \rightarrow 3)-\beta-D-$ glucan, in the absence of any other protein (Muta et al., 1995). The resulting active factor $\overline{\mathrm{G}}$ activates proclotting enzyme directly, resulting in coagulin gel formation (Takaki et al., 2002). Recently, Osaki et al., (2002) found that non-covalent coagulin homopolymers are cross-linked by bridging hemocyte cell surface proteins, named proxins (Table 2), in the presence of hemocyte-derived transglutaminase (Tokunaga et al., 1993; Osaki and Kawabata, 2002). This indicates that cross-linking is important at the final stage of hemolymph clotting to facilitate hemostasis and wound healing, as has been reported in the mammalian blood clotting system (Iwanaga, 1993a,b).

Interestingly, the $\mathrm{NH}_{2}$-terminal portions of zymogen factor $\mathrm{B}$ and of proclotting enzyme contain a small compact domain containing three disulfide bonds, called the "clip domain" (Muta and Iwanaga, 1996). A similar "clip domain" has also been reported in the $\mathrm{NH}_{2}$-terminal proenzyme regions of Drosophila-derived serine proteases, as described later. Moreover, the folding pattern of the three disulfide bridges located in the "clip domain" is identical to that of "big defensin", which was recently identified as an antimicrobial peptide in T. tridentatus hemocytes. As the $\mathrm{COOH}$-terminal end of the "clip domain" in proclotting enzyme constitutes a hinge region susceptible to proteolysis, the "clip domain", in the same manner as defensin, might be released during the activations of serine protease zymogens, in order to act as an antimicrobial substance. In fact, the "clip domain" derived from the prophenoloxidase activated serine protease of freshwater crayfish has an antimicrobial activity similar to that of human $\beta$-defensin (Wang et al., 2001). Thus, the clotting cascade could also produce antimicrobial agents, and thus provide a dual action clotting and killing system against invaders (Krem and Docera, 2002; Theopold et al., 2004).

As described later in detail, the prophenoloxidase activation system found in insects (Ashida and Brey, 1998) and

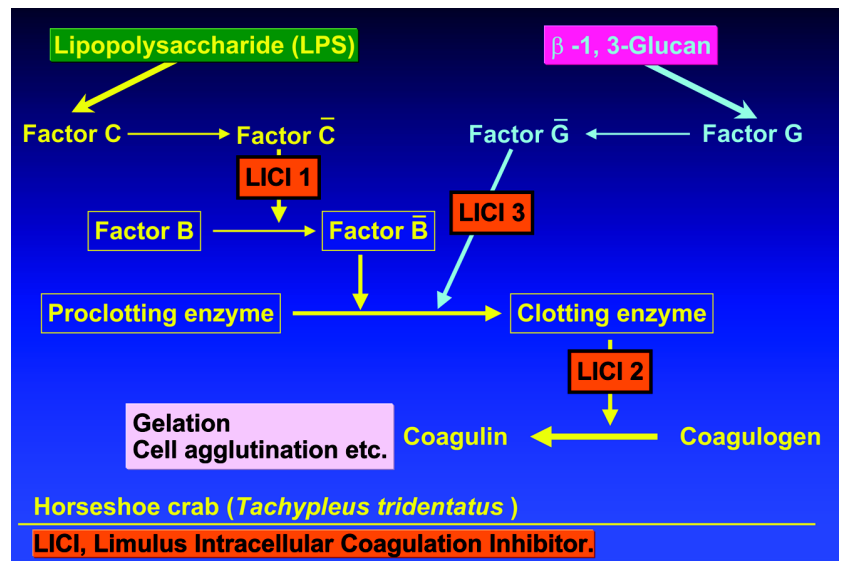

Fig. 4. LPS- and $(1 \rightarrow 3)$ - $\beta$-D-glucan mediated clotting cascades found in horseshoe crab (T. tridentatus) hemocytes. LICI, limulus intracellular coagulation inhibitor. This figure depicts the biochemical principle of the so called limulus test, which is used for detecting bacterial endotoxins. The method was developed by Levin and Bang (1964) based on a finding that a trace amount of endotoxin coagulates the hemocyte (amebocyte) lysate of the American horseshoe crab, Limulus polyphemus. This gelation reaction has been widely employed as a simple and highly sensitive assay for endotoxins (LPS). The limulus test is dependent on the protease cascade reaction shown in the figure, and is being used extensively in combination with new technology (Iwanaga et al., 1978, Tanaka and Iwanaga, 1993, Obayashi et al., 1985).

crustaceans is an important aspect of innate immunity, and functions to detect and kill invading pathogens and to produce melanin and its derivatives to encapsulate invaders and facilitate wound healing (Fig. 1). Recently, Decker and Tuczek reported that hemocyanin of the tarantula Eurypelma californicum expresses phenoloxidase activity after limited proteolysis with trypsin and $\alpha$-chymotrypsin (Decker and Tuczek, 2000). Furthermore, hemocyanins of the crab Carcinus maenas and the lobster Homarus Americanus also express significant phenoloxidase activity in the presence of perclorate. Moreover, the phenoloxidase activities of the hemocyanins of the horseshoe crab Limulus polyphemus (Nellaiappan and Sugumaran, 1996) and T. tridentatus are induced in the presence of sodium dodecylsulfate and phosphatidylethanolamine (Sugumaran, 2002). Nagai and Kawabata (2000) also found that the clotting cascade of $T$. tridentatus is linked to prophenoloxidase activation, with the oxygen carrier hemocyanin functioning as a prophenoloxidase substitute. Active clotting enzyme or factor $\overline{\mathrm{B}}$ (active form) functionally transform hemocyanin to phenoloxidase, and this conversion plateaus at a stoichiometry of $1: 1$ without proteolytic cleavage. Interestingly, proclotting enzyme also induces hemocyanin based phenoloxidase activity, but neither factors $\mathrm{C}$ nor $\mathrm{G}$ zymogens have any effect on hemocyanin. Although the functional roles of these links between the clotting cascade and hemocyanin-based phenoloxidase systems in vivo is not clear, these results suggest that 


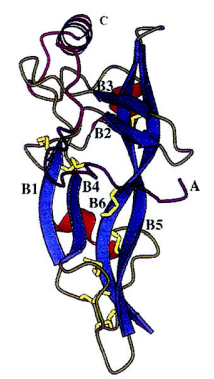

Coagulogen

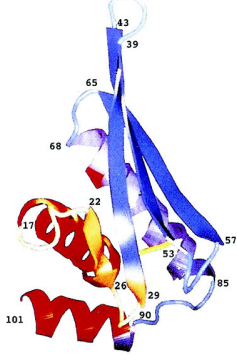

Anti-LPS factor

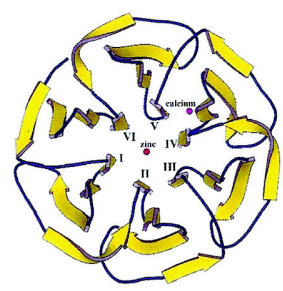

Tachylectin 1

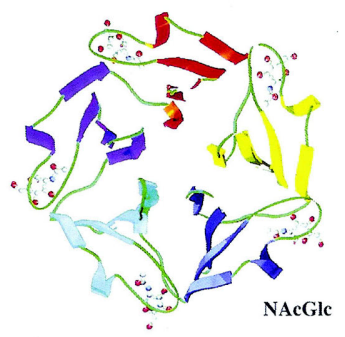

Tachylectin 2

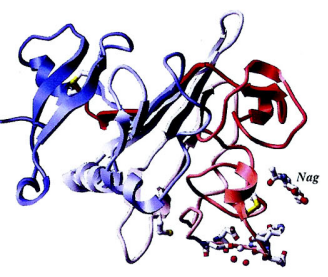

Tachylectin 5A

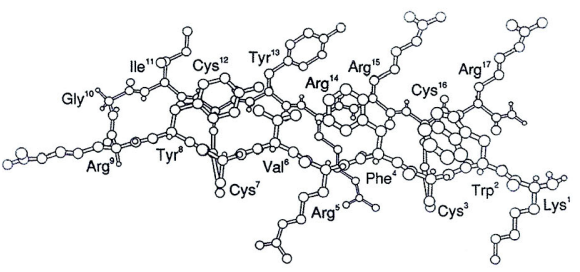

Tachyplesin

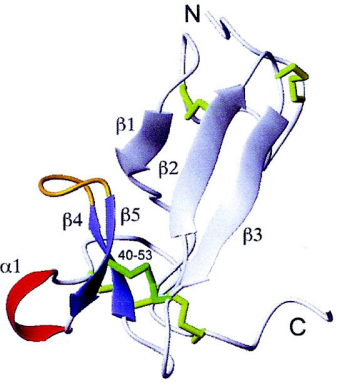

Tachycitin

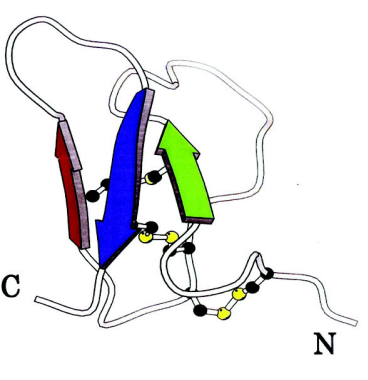

Tachystatin A

Fig. 5. The 3D structures of major defense molecules isolated from T. tridentatus hemocytes and hemolymph plasma. Coagulogen, tachylectins 1 and 2, and anti-LPS factor are stored in L-granules. The antimicrobial peptides, tachyplesin, tachycitin, and tachystatin A are located in S-granules. Tachylectin 5A is mainly found in hemolymph plasma.

hemocyanin exists abundantly in hemolymph plasma and that it may participate in the innate immune system of the horseshoe crab (Nagai et al., 2001).

Lectin-agglutinin system The innate immune system of the horseshoe crab also recognizes invading pathogens by using a combinatorial method involving lectin-agglutinis with different specificities components exposed on the surfaces of pathogens (Crouch et al., 2000; Chiou et al., 2000; Kawabata et al., 2001). As shown in Table 2, five types of lectins (tachylectins(TL)-1 to 5), three types of C-reactive proteins with different binding specificities to phospholipids, and several agglutinins have been identified in circulating hemocytes and hemolymph plasma (Kawabata and Iwanaga, 1999; Kawabata and Tsuda, 2002). These components function synergistically to form an effective host defense against invading microbes and foreign substances.

Of these agglutin-lectins, hemocyte-derived TL-1 interacts with Gram-negative bacteria probably via 2-keto-3-deoxyoctonate (KDO), a constituent of bacterial LPS, and was found to cause the agglutination of sheep erythrocytes coated with LPS (Saito et al., 1995). TL-1 is a single-chain protein of 221 amino acid residues with no $N$-linked sugar chain, and contains three intra-chain disulfide bonds and a free cysteine residue. The six tandem repeats of TL-1 are an outstanding structural feature. TL-1 exists as a monomer in solution, and the 3D structure of TL-1 is dominated by six $\beta$ sheets, which correspond to the six tandem repeats (Fig. 5). TL-1 has a six-bladed propeller structure with a central zinc atom coordinated with three aspartate residues, two serine residues and one molecule of water. The center of TL- 1 also contains a cluster of six lysine residues one in each of the six repeated structures, which form a hole allowing interactions with trisaccharides containing KDO (for more details see, Saito et al., 1995; Kawabata and Iwanaga, 1999).

TL-2 is a unique lectin and has hemagglutinating activity against human A-type erythrocytes (Okino et al., 1995). TL-2 binds specifically to GlcNAc with a dissociation constant of $0.05 \mathrm{mM}$. A detailed sugar-binding analysis indicated that the acetamide group at the $\mathrm{C}-2$ position and the free $\mathrm{OH}$ group at the C-4 position of GlcNAc are required for recognition by TL2. The most interesting feature of the 236 amino acid TL-2 sequence is the five tandem 47 amino acid repeats. Moreover, TL-2 does not contain cysteine or $N$ - or $O$-linked sugars, and is present as a monomer in solution. The X-ray structure of TL-2 complexed with GlcNAc has been elucidated at a resolution of 
2.0^̊ (Fig. 5). TL-2 has a five-bladed $\beta$-propeller structure and its single chain is organized into five sheets, arranged in consecutive order with five-fold rotational symmetry around a central tunnel (Beisel et al., 1999). The structure contains five equivalent binding sites, with virtually identical occupancies and geometries in the crystal.

GlcNAc points its acetamide group toward the bottom of the TL-2 binding pocket, whereas the $\mathrm{C6}-\mathrm{OH}$ group is directed out into the medium. Moreover, TL-2 shows virtually no change in main or side chain conformation after binding GlcNAc. The nature of its binding pocket explains its strict specificity toward GlcNAc. Thus, the presence of five binding sites per TL-2 molecule suggest that it recognizes pathogens with a fairly high ligand density of GlcNAc units. Moreover, the multiple binding of the five binding sites to repetitive structures on pathogens would generate strong interactions, indicative of a type of pattern recognition.

TL-3 exhibits hemagglutinating activity specifically against human A-type erythrocytes. The hemagglutinating activity of TL-3 is equivalent to that of TL-2, but its activity is not inhibited by $D$-GlcNAc or $D$-GalNAc (Saito et al., 1997). Interestingly, its hemagglutinating activity is completely inhibited by a synthetic pentasaccharide derivative of blood group A antigen and more strongly inhibited by the S-type LPSs of several Gram-negative bacteria in the concentration range $5-10 \mathrm{ng} / \mathrm{ml}$, but not by the corresponding R-type LPSs, which indicates that TL-3 has high specificity against Oantigens. Moreover, TL-3 contains 123 amino acid residues in the form of two repeating sequences and is present as a dimer in solution (Saito et al., 1997).

TL-4 is a $470 \mathrm{kDa} 232$ amino acid oligomeric glycoprotein (Inamori et al., 1999), and its hemagglutinating activity against human A-type erythrocytes is more potent than those of TL-2 and TL-3. Although $L$-fucose and $N$-acetylneuraminic acid at $100 \mathrm{mM}$ completely inhibits this activity, TL-4 is more strongly inhibited by bacterial S-type LPS, but is not inhibited by R-type LPS, which lacks O-antigen. Thus, colitose (3deoxy- $L$-fucose), a unique sugar present in the O-antigen of $E$. coli O111: B4, and which is structurally similar to $L$-fucose, is a likely specific TL-4 ligand.

Of the five types of plasma-derived tachylectins, TL-5A and TL-5B have greatest hemolymph agglutinating activities, and exhibit broad specificity for substances containing $N$ acetyl groups (Gokudan et al., 1999). TL-5A and TL-5B agglutinate all types of human erythrocytes, indicating that the primary recognition substance is not a blood group antigen. Their hemagglutinating activities are inhibited by $5 \mathrm{mM}$ EDTA, and this inhibition is neutralized by adding an excess of $\mathrm{CaCl}_{2}$. Both TL-5A and TL-5B specifically recognize acetyl group-containing substances including noncarbohydrates; only the acetyl group is required for recognition. They also strongly agglutinate Gram-negative and-positive bacteria. The overall sequence identity between the 269 amino acid residues of TL-5A and the 289 residues of TL-5B is $45 \%$, and they share sequence similarity with the $\mathrm{COOH}$-terminal fibrinogen- like globular domain. Interestingly, a collagenous domain in ficolins is missing in the corresponding regions of TLs-5A and $-5 \mathrm{~B}$. Thus, since ficolin-like mannan-binding lectin is known to participate in a novel lectin pathway of the complement system (Matsushita and Fujita, 2001; Lindahl et al., 2000), TLs-5A and -5B, both structural homologs of ficolin, may also trigger the activation of the horseshoe crab complement system (Fujita, 2002; Gadjeva et al., 2001). The 3D structure of TL-5A complexed with GlcNAc has been recently elucidated using the multiple isomorphous replacement technique (Fig. 5). It is an ellipsoidal molecule with overall dimensions of ca. $34 \times 36 \times 53 \AA$, and is subdivided into three distinct interacting domains (Kairies et al., 2001). TL-5A contains a $\mathrm{Ca}^{2+}$-binding site and an acetyl group-binding pocket. In addition, a systematic computer search performed with SCOP revealed that TL-5A is structurally related to the fibrinogen $\gamma$-chain fragment (rms deviation of $1.09 \AA$, overall), thus verifying our previous prediction based on amino acid sequence similarity that TL-5A showed the highest sequence identity (53\%) to that of mammalian ficolins (Gokudan et al., 1999). Electron microscopy showed that TL-5A forms a three- or four-bladed propeller structure, and that TL-5B has a two-bladed propeller structure. If their ligand binding sites are located in their blades, TLs-5A and $-5 \mathrm{~B}$ could be more potent against high-density ligands on pathogens, and their polyvalent binding of acetyl-groups a key factor of microorganism binding. In addition they function as non-self-recognizing proteins.

The hemolymph of horseshoe crabs contains another class of bacterial agglutinins, which is structurally related to mammalian CRP (Iwaki et al., 1999). CRP was first recognized in human plasma as a non-immunoglobulin capable of precipitating with C-polysaccharides derived from the cell wall of Streptococcus pneunomiae. Limulin, a sialic acidand phosphorylethanolamine-binding hemagglutinin in the hemolymph plasma of L. polyphemus, is a hemolytic CRP (Table 2). Three types of CRPs have been purified from the plasma of $T$. tridentatus, by using their different affinities for fetuin-agarose and phosphorylethanolamine-agarose. These CRPs are named $T$. tridentatus CRP-1 (tCRP-1), tCRP-2, and tCRP-3, each of which consists of several isoproteins. tCRP-2 and tCRP-3, but not tCRP-1, agglutinate mammalian erythrocytes. tCRP-1 is the most abundant CRP, and exhibits highest affinity for phosphorylethanolamine-protein conjugate but lacks both sialic acid-binding and hemolytic activities. tCRP1 binds to both fetuin-agarose and phosphorylethanolamineagarose, and exhibits $\mathrm{Ca}^{2+}$-dependent hemolytic and sialic acid-binding activities. Furthermore, tCRP-2 exhibits a higher affinity to colominic acid, a bacterial polysialic acid, though tCRP-3 shows stronger hemolytic, sialic acid-binding and hemagglutinating activities than tCRP-2. However, tCRP-3 has no affinity for phosphorylethanolamine-agarose or colominic acid. Thus, tCRP-3 is a novel hemolytic CRP, which lacks the common characteristic of CRPs, namely, the ability to bind phosphorylethanolamine-agarose. Twenty-two clones of tCRPs 
with different deduced amino acid sequences showing high levels of molecular diversity have been identified (Iwaki et al., 1999). Moreover, of these tCRP clones only tCRP-3 contains a unique hydrophobic nonapeptide sequence that appears in the transmembrane domain of a major histocompatibility complex class I heavy chain of rainbow trout, which suggests that their hydrophobic nonapeptide patch is important for the hemolytic activity of tCRP-3. The structural and functional diversities of tCRPs offer an interesting model for the study of invertebrate innate immunity, which allows survival without the benefit of acquired immunity.

Antibacterial, antifungal, and antiviral systems The Sgranules of $T$. tridentatus hemocytes contain a family of arthropodous peptide antibiotics, called the "tachyplesin" family, in addition to tachycitins, tachystatins, and $\beta$-defensin analogs (Table 2). Moreover, the L-granules of $T$. tridentatus were found to contain an antibacterial protein, called anti-LPS factor, factor D and big defensin (Fig. 3). The S-granulederived peptides antibiotics bind chitin, but no other polysaccharides, e.g., cellulose, mannan, xylan, or laminarin. One of these antimicrobial peptides (Table 2) tachyplesin, which consists of 17 amino acid residues, was found to significantly inhibit the growth of Gram-negative and positive bacteria and fungi (Iwanaga et al., 1998; Morvan et al., 1997). Tachyplesin has a rigid hairpin loop that is constrained by two disulfide bridges and adopts an antiparallel $\beta$-sheet conformation connected to a $\beta$-turn (Fig. 5). In its planar conformation, the five hydrophobic side chains are localized on one face, and the six cationic side chains on another. Thus, the amphiphilic structure of tachyplesin is presumed to be closely associated with its antibacterial activity.

Big defensin, which consists of 79 residues, is unlike mammalian defensins in terms of its size (though they have 29-34 residues in common), and is proteolytically divided into two domains by trypsin. Moreover, its $\mathrm{COOH}$-terminal domain shows sequence similarity with mammalian neutrophilderived $\beta$-defensins. In fact, the disulfide motif in this domain is identical to that of bovine neutrophil $\beta$-defensin. One noteworthy characteristic of $T$. tridentatus big defensin is that its two domains are functionally different. Big defensin has antimicrobial activity against both Gram-negative and positive bacteria. Interestingly, its $\mathrm{NH}_{2}$-terminal hydrophobic domain is more effective than its $\mathrm{COOH}$-terminal defensin domain against Gram-positive bacteria, whereas its $\mathrm{COOH}-$ terminal domain more potent against Gram-negative bacteria, which suggests that big defensin is a chimeric defense molecule. Thus, big defensin in T. tridentatus may represent a new class of the defensin family, possessing two functional domains with different antimicrobial activities.

Tachystatins A, B, and C, consist of 41-44 residues, and exhibit broad-spectrum antimicrobial activity against fungi and Gram-negative and -positive bacteria (Osaki et al., 1999).

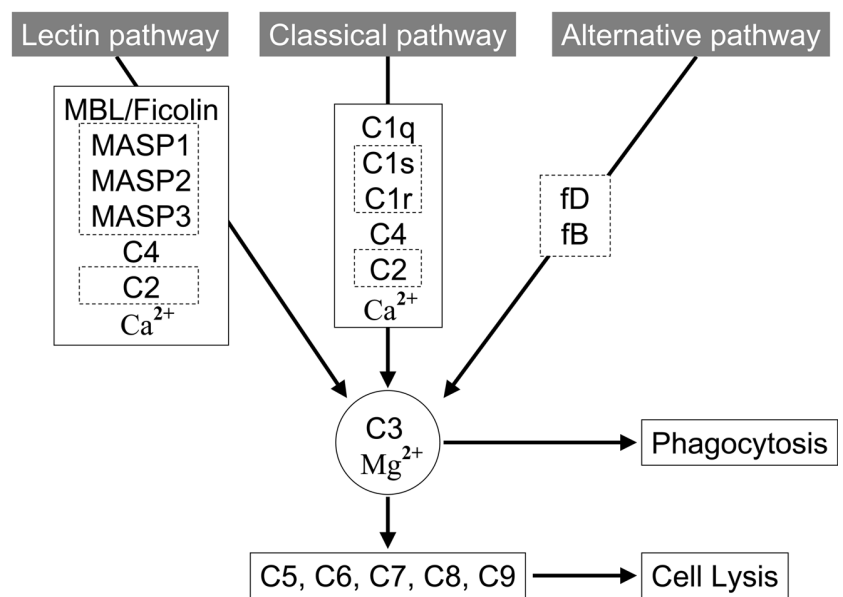

Fig. 6. Outlines of the classical, lectin, and alternative pathways of complement activation. The complements boxed and scored are serine proteinases. MBL, mannose binding lectin; MASP, mannose-binding lectin-associated serine protease.

Of these three, tachystatin $\mathrm{C}$ is the most effective, and tachystatin A is homologous to tachystatin B. Tachystatin C contains the same disulfide motif found in tachystatin $\mathrm{A}$, but shares low sequence similarity with tachystatin $\mathrm{A}$, which shares sequence similarity with $\omega$-agatoxin-IVA of funnel web spider venom, a potent blocker of voltage-dependent calcium channels. However, tachystatin A does not block P-type calcium channel activity in rat Purkinje cells. Tachystatins cause morphologic changes in budding yeast, and tachystatin $\mathrm{C}$ has strong cell lysis activity. Furthermore, tachystatin $\mathrm{C}$, but not $\mathrm{A}$ and $\mathrm{B}$, has hemolytic activity, and shows sequence similarity with several arachnid neurotoxins. Thus, as horseshoe crabs are close relatives of spiders, tachystatins and spider neurotoxins may have evolved from a common ancestral peptide. Recently, the 3D structure of tachystatin A was determined by NMR (Fig. 5), and its 2D structure was found to contain a cysteine-stabilized triple-standard $\beta$-sheet domain which undergoes amphiphilic folding to form the $3 \mathrm{D}$ structure as is observed for many membrane-interactive peptides (Fujitani et al., 2002). Interestingly, tachystatin A shares 3D structural similarities with $\omega$-agatoxin IVA. These structural comparisons and functional correspondences suggest that the antifungal activities of both peptides mechanistically resemble those of defensins.

Tachycitin consists of 73 amino acid residues that contain five disulfide bonds each with no $N$-linked sugar (Kawabata $e t$ al., 1996). Moreover, although its antimicrobial activity is only moderate, tachycitin synergistically enhances the antimicrobial activity of big defensin, for example the $\mathrm{IC}_{50}$ value of big defensin against Gram-negative bacteria reduces by a factor of 50 in the presence of small amounts of tachycitin. As shown in Fig. 5, the 3D structure of tachycitin is largely composed of $\mathrm{NH}_{2^{-}}$and $\mathrm{COOH}$-terminal domains (Suetake et al., 2000). In the latter, tachycitin forms a hairpin 
Table 3. Major defense molecules found in hemocytes, hemolymph plasma and tissues of the fresh water crayfish (Pacifastacus leniusculus)

\begin{tabular}{|c|c|c|}
\hline Proteins and peptides & $\operatorname{Mass}(\mathrm{kDa})$ & Function \\
\hline \multicolumn{3}{|l|}{ Prophenoloxidase system } \\
\hline Prophenoloxidase(ProPO) & 76 & Precursor of phenoloxidase and melanin formation. Serine protease \\
\hline ProPO activating enzyme (ppA) & 48 & which contains $\beta$-defensin-like domain. \\
\hline \multicolumn{3}{|c|}{$\begin{array}{l}\text { LPS and } \beta 1,3 \text {-glucan binding proteins } \\
\text { (LGBP) }\end{array}$} \\
\hline$\beta$ 1,3-glucan binding protein & 100 & $\begin{array}{l}\text { One of the triggers of prophenoloxidase activating system } \\
\text { (ProPO system). }\end{array}$ \\
\hline LGBP & 40 & Involvement in ProPO system. Opsonin and cell adhesion. \\
\hline Mannose-binding lectin & 28 & secreted from hemocytes upon challenge. \\
\hline \multicolumn{3}{|l|}{ Cell adhesion proteins } \\
\hline Peroxnectin & 76 & Cell adhesion molecule and, binding to peroxidase. \\
\hline Masquerade-like protein 1 & $124 / 134$ & $\begin{array}{l}\text { Cell adhesion protein which contains non-catalytic serine protease } \\
\text { domain. }\end{array}$ \\
\hline Masquerade-like protein 2 & 40 & secreted from hemocytes upon challenge. \\
\hline \multicolumn{3}{|l|}{ Proteinase inhibitor } \\
\hline$\alpha_{2}$-Macroglobulin & $190 \times 2$ & Complement-like activity. \\
\hline Pacifastin & 155 & Serine protease inhibitor which contains a unique transferring chain. \\
\hline Subtilisin inhibitor & 28 & \\
\hline Kazal-type inhibitors & $10-30$ & Four domains-Kazal type protease inhibitor. \\
\hline \multicolumn{3}{|l|}{ Antibacterial proteins } \\
\hline Lysozyme & 14 & Cell lysis. \\
\hline Hemagglutinin & 420 & Hemaggultinating activity. \\
\hline Cytosolic ferritin & 440 & A storage protein for ferric ion. \\
\hline Astocidine 1 & 1.6 & Antimicrobial peptide. \\
\hline Astocidine 2 & 1.8 & Antimicrobial peptide. \\
\hline Curcinine-like peptides & $14-20$ & Antimicrobial peptide. \\
\hline Anti-LPS factor & 13.5 & secreted from hemocytes upon challenge. \\
\hline \multicolumn{3}{|l|}{ Others } \\
\hline Vitellogenin-related protein & $210 \times 2$ & A plasma clotting protein, lipoprotein-like, and TGase substrate. \\
\hline Transglutaminase (TGase) & 90 & Cross-linking. \\
\hline Hemocyanins & 360 & $\begin{array}{l}\mathrm{O}_{2} \text { transporter, phenoloxidase-like activity, and produces anti-microbial } \\
\text { peptides. }\end{array}$ \\
\hline Astakine & 8.7 & Cytokine-like activity in hematopoiesis. \\
\hline
\end{tabular}

loop of a two-stranded $\beta$-sheet, which superimposes the structure of the chitin-binding site of hevein without any sequence similarity. Hevein is an antifungal peptide that was isolated from the rubber tree Havea basiliensis. Tachyplesin like tachycitin also has strong chitin-binding ability, and contains a similar hairpin loop in a two-stranded $\beta$-sheet (Fig. 5). In both tachycitin and tachyplesin hydrophobic residues clustered on the one face of the $\beta$-hairpin loops probably function as the chitin-binding site. Chitin is a component of the cell wall of fungi, and is also a major structural component of arthropod exoskeletons. Thus, the antimicrobial substances released from $T$. tridentatus hemocytes probably recognize chitin exposed at the site of a lesion, and appear to function in wound healing and as antibacterial molecules, in addition, they may stimulate and accelerate biosynthesis of chitin at sites of injury.

\section{The freshwater crayfish (Pacifastacus (P) leniusculus)}

Much progress has been achieved on the innate immune system of fresh water crayfish, Pacifastacus leniusculus (Fig. 2B) by Söderhäll and his colleagues (Söderhäll et al., 1996). Here, we focus on the prophenoloxidase activating system (the pro-PO system) and the non-self recognition system, both of which have important roles in host defense.

The pro-PO activating system Table 3 summarizes the various defense proteins and peptides found in crayfish hemolymph and tissues. The crayfish pro-PO system consists of 
several proteins that participate in melanin formation, cytotoxic reactions, cell adhesion, encapsulation, and phagocytosis. A similar immune system is found in many other invertebrates, such as, insects, ascidians, mollusks, echinoderms, millipedes, bivalves, and brachiopods (Söderhäll et al., 1994; Cannon et al., 2004). It is an efficient non-self recognition system and is initiated by the recognition of the LPSs or peptidoglycans of bacteria and $(1 \rightarrow 3)-\beta$-D-glucans of fungi. The pro-PO system of $P$. leniusculus, which is similar to those of insects described later, is composed of a protease cascade composed of a pattern of recognition proteins (LPS and $(1 \rightarrow 3)-\beta$-D-glucan binding proteins), several serine protease, their zymogens, and pro-PO (Table 3). The active form of pro-PO, phenoloxidase, also known as tyrosinase, catalyzes two successive reactions; the first is the hydroxylation of a monophenol to an O-diphenol, and the second is the oxidation of O-diphenol to O-quinone (Sugumaran, 2002). The production of toxic quinone intermediates and O-quinones by phenoloxidase is an initial step in the biochemical cascade of melanin biosynthesis, and is also important in cuticular scleotization, wound healing, and in the encapsulation of foreign materials for host defense (Cerenius and Söderhäll, 2002). During the last five years, structural information about pro-PO activating enzymes (serine protease) have become available. In crayfish, pro-PO is synthesized and localized in hemocyte granules and then released into plasma by exocytosis triggered by pattern recognition proteins (Table 3$)$. The so called $(1 \rightarrow 3)-\beta-\mathrm{D}-$ glucan/LPS binding proteins (Cerenius et al., 1994), are the triggering molecules of the crayfish pro-PO system, since they bind microbial cell wall components and induce the activation of serine protease zymogens in the pro-PO system (Lee et al., 2000). The serine proteases of the crayfish pro-PO system contain one "clip domain", which shows homology with horseshoe crabderived big defensin and mammalian $\beta$-defensin mentioned before. This "clip domain" is cleaved upon activation by upstream proteases (Wang et al., 2001). Moreover, the cleaved "clip domain" in crayfish shows antibacterial activity in vivo against Gram-negative bacteria, which suggests that the pro-PO activating serine proteases have a dual function.

The pro-PO system is controlled carefully by regulating proenzyme activation and phenoloxidase activity, in which it produces highly toxic quinone intermediates (Johansson et al., 1995). This control is achieved partially by inactive zymogen, which is activated by proteolysis (Wang et al., 2001). Zymogen is stored in circulating hemocytes in the crayfish, and to avoid excessive or premature activation, protease inhibitors also play an important role, as they do in the regulation of the $T$. tridentatus clotting cascade (Fig. 4). In the case of the freshwater crayfish detailed biochemical data is available on the manner in which such inhibitors regulate the activation of the pro-PO system. One of the most efficient serine protease inhibitors is a $155 \mathrm{kDa}$ heterodimeric protein with a unique structure, named pacifastin (Liang et al., 1997). It is composed of one heavy chain with transferrin lobes and one protease inhibitor-light chain, which are covalently linked to each other. Interestingly, the pacifastin light chain shares a characteristic cysteine array with a family of monomeric low molecular weight protease inhibitors of the serpin type; moreover, this cysteine array has not been found in other protease inhibitors. As the crayfish-derived inhibitor was the first member of this family isolated, these inhibitors are now commonly referred to as members of the pacifastin family of protease inhibitors. Other inhibitors also present in crayfish hemolymph plasma have some capacity to restrict serine protease activity, such as $\alpha_{2}$-macroglobulin and Kazal inhibitor (Johansson et al., 1994) (Table 3).

Pattern-recognition molecules As described previously, the presence of minute quantities of microbial surface components, such as $(1 \rightarrow 3)-\beta$-D-glucan or peptidoglycan, are enough to trigger the activation of the pro-PO system. A large number of pattern-recognition molecules with affinities for bacterial and fungal cell wall components that mediate pro-PO system activation have been identified. In freshwater crayfish, two separate pattern-recognition proteins, namely, $(1 \rightarrow 3)-\beta-D-$ glucan binding protein and masquerade-like protein are known (Huang et al., 2000), and their structure-function relationships have been studied in detail (Cerenius et al., 2003). Of these, the latest to be identified has structural properties that are similar to those of Drosophila-derived masquerade; a serine protease homologue expressed during embryogenesis, laval, and pupal development in D. melanogaster (Lee and Söderhäll, 2001). The freshwater crayfish masquerade-like protein binds to formaldehyde (HCHO)-treated Gram-negative bacteria and HCHO-treated yeast (Saccharomyces cerevisiae), but not to HCHO-treated Gram-positive bacteria. Intact masquerade-like protein is present in crayfish hemocytes as a heterodimer of $134 \mathrm{kDa}$ and $129 \mathrm{kDa}$ subunits (Table 3). After binding to bacterial or yeast cell walls, this protein is processed by a proteolytic enzyme. The $134 \mathrm{kDa}$ subunit yields four fragments of $64,47,33$ and $29 \mathrm{kDa}$, and the $129 \mathrm{kDa}$ subunit results in four fragments of $63,47,33$ and $29 \mathrm{kDa}$. Of these fragments, the $33 \mathrm{kDa}$ fragment derived from the $\mathrm{COOH}$-terminal part of masquerade-like protein has cell adhesion activity. E. coli coated with masquerade-like protein are more rapidly cleared in crayfish than $E$. coli alone, which suggests that masquerade-like protein is an opsonin-like protein.

Proteins with components similar to those of Drosophila and freshwater crayfish masquerade proteins, with serine proteaseinactive homologues, have been identified in vertebrates and invertebrates, and have been suggested to have various biological activities, e.g., antimicrobial activity (human azurocidin, horseshoe crab factor D (Table 1) (Kawabata et al., 1996)), growth factor activity (hepatocyte growth factor), adhesion promoting activity (fruit fly glutactin, neurotactin, and masquerade), and immune activity (mosquito infection-responsive serine protease-like protein). These molecules show homology to serine proteases, except for catalytic residue substitutions. Therefore, the cell adhesion and opsonic activities of freshwater crayfish masqueradelike protein suggest that it plays a significant role in the innate immune system of this animal. 
Table 4. Major defense molecules and complements and its genes identified in an ascidian

(A) Various defense molecules (Halocynthia roretzi)

Phenoloxidase $(62 \mathrm{kDa})$ released from hemocytes.

Membrane glycoprotein $(160 \mathrm{kDa})$, named A74 protein, one of the adhesion molecules.

Galactose-specific lectin $(600 \mathrm{kDa})$.

$\mathrm{N}$-Acetylglucosamine-specific lectin $(50 \mathrm{kDa})$.

$\mathrm{N}$-Acetylgalactosamine-specific lectin $(500 \mathrm{kDa})$.

Trypsin inhibitors $(8 \mathrm{kDa})$.

LPS-binding hemagglutinin $(120 \mathrm{kDa})$.

Antimicrobial substances-Helocyamins

(0.6kDa, 3,4 dihydroxyphenylalanine (DOPA) containing peptides)

(B) Complements and its genes (Halocynthia roretzi and Ciona intestinalis)

Collectin/Ficolin

$\mathrm{MASP} / \mathrm{C} 1 \mathrm{~s} / \mathrm{C} 1 \mathrm{r}$

$\mathrm{C} 3 / \mathrm{C} 4 / \mathrm{C} 5 / \alpha_{2}-$ Macroglobulin

$\mathrm{Bf} / \mathrm{C} 2$

C6/C7/C8/C9/Perforin

Other defense proteins and structural domains predicted from genomic analysis (Ciona intestinalis)

Pentaxin, Cytokines (TNF), Toll-like receptors (three receptors), MyD88, IRAK, TRAF, IP105, NFkB, IкB, Immunoglobulin superfamily molecules (VCBP, Peroxidasin, Nectin, JAM/CTX, CD166), Fibrinogen-C, Sushi (SCR), C-type lectin, CUB, Integrin $\beta$, EGF, CD36, C1q, CD94.

The abbreviations: TNF, tumor necrosis factor; IRAK, IL-1 receptor-associated kinase; TRAF, TNF receptor-associated factor; MASP, mannose-binding lectin-associated serine protease; SCR, short consensus repeat; CUB, C1r/Uegf/Bone morphogenetic protein 1.

Freshwater crayfish plasma clotting protein As described earlier, vertebrates and invertebrates have separately evolved efficient molecular mechanisms to immediately form blood clots (Iwanaga, 1993, Theopold et al., 2004), which is essential to prevent blood/hemolymph loss in case of injury. Vertebrates have similar clotting systems, which result in the proteolytically induced aggregation of fibrinogen into insoluble fibrin. These noncovalently-associated fibrin aggregates are further stabilized by the formation of intermolecular covalent cross-links in the presence of factor XIIIa (transglutaminase) and $\mathrm{Ca}^{2+} \cdot \mathrm{Ca}^{2+}$-dependent factor XIIIa catalyses covalent cross-linking to form an $\varepsilon$ ( $\gamma$-glutamyl) lysine between the side chains of specific lysine and glutamine residues on certain proteins (Tokunaga and Iwanaga, 1993). In the crayfish, hemolymph clotting is based on the direct transglutaminasemediated cross-linking of a specific plasma protein, which is homologous to the vitellogenins (Hall et al., 1995). Freshwater crayfish clotting protein is a lipoprotein that consists of 1,721 amino acids $(210 \mathrm{kDa} \times 2$, Table 3$)$ and shares limited sequence similarity with other lipoproteins, such as mammalian apolipoprotein B and microsomal triglyceride transfer protein. It also contains a stretch with similarity to the D domain of von Willebrand factor (Hall et al., 1999). Each of its $210 \mathrm{kDa}$ subunits has lysine and glutamine side chains, which are covalently cross-linked to each other by transglutaminase. Hemolymph clotting is induced when a transglutaminase is released from hemocytes or tissues, and starts cross-linking plasma-derived clotting protein in the presence of $\mathrm{Ca}^{2+}$. Moreover, crayfish clotting protein exists in both sexes, unlike the female-specific vitellogenins. In the presence of an endogenous transglutaminase, clotting protein molecules rapidly assemble into long and flexible chains that occasionally branch, as evidenced by electron microscopy. Despite its similar functions, clotting protein appears not to share any structural similarities with mammalian fibrinogen or horseshoe crab coagulogen. This indicates that crayfish clotting protein and lobster fibrinogen, which share sequence similarity with the vitellogenins, constitute a separate group of clotting factors. Thus, the crustacean clotting proteins are a second type of gel-forming proteins and are evolutionary related to vitellogenins, but they should not be considered as true vitellogenins, since they have completely different functions and are constitutively expressed in both sexes.

\section{The solitary ascidian (Halocynthia $(\mathrm{H})$ roretzi)}

Ascidians are intriguing invertebrates from the viewpoint of the evolution of the innate immune system (Azumi et al., 2003), not least because they lack acquired immunity. The ascidians belong to the protochordata, and occupy a phylogenetic position between vertebrates and invertebrates. Of the ascidians, the largest in size is the solitary ascidian, $H$. roretzi, which inhabits the seas around Japan (Fig. 2C); large quantities of hemolymph and numbers of hemocytes can be obtained from the cavity of this animal. Biochemical studies on the cellular defense mechanisms used by ascidians have been mainly performed by Azumi and Yokosawa group. In $H$. roretzi, hemocytes show several cellular reactions, such as, 
hemocyte aggregation, phagocytosis, self and non-self recognition reactions, and phenoloxidase enzyme release in response to stimuli (Takahashi et al., 1995). Table 4A shows major hemolymph-derived components that are involved in $H$. roretzi host defense. Of these components, phenoloxidase is contained in hemocytes and is released from hemocytes by treatment with zymosan or LPS, but not by $(1 \rightarrow 3)-\beta$-Dglucan (Hata et. al., 1998). Like other phenoloxidases derived from crayfish and insects, $H$. roretzi phenoloxidase is a metalloenzyme that requires copper ions for full activity (Hata et al., 1998). Interestingly, the phenoloxidase shows antibacterial activity against $E$. coli in the presence of $L$-(3,4-dihydroxy) phenylalanine (DOPA), which suggests that phenoloxidase catalyzes the formation of antibacterial substances from DOPA (see Table 4 (A)). Thus, hemocyte-derived phenoloxidase functions as a humoral factor in the host defense of $H$. roretzi.

On the other hand, as shown by Table 4(B), a number of possible complement genes have recently been identified in the ascidian Ciona itestinalis (Azumi et al., 2003). In higher vertebrates, about 35 proteins are known to function in the three complement activations of the classical, alternative, and lectin pathways (Fig. 6) (Fujita, 2002, Caroll, 2004). Thus, it was surprising to learn that almost the same number of complement components are present in ascidians (Nonaka, 2001). In support of these findings, biochemical evidence now demonstrates the presence of mammalian-like alternative and lectin pathways in tunicates (Smith et al., 1999), and in sea urchins (Smith, 1999, Kenjo et al., 2001). In H. roretzi cDNA clones of third complement (C3), mannose-binding lectin associated serine protease (MASP), and factor $\mathrm{B}(\mathrm{Bf})$ were isolated from ascidian hepatopancreas cDNA library (Nonaka and Azumi, 1999). The deduced primary structure of ascidian complement $\mathrm{C} 3$ shows an overall similarity with mammalian C3, and contains a typical thioester site. Moreover, two distinct ascidian MASPs, namely, AsMASPa and AsMASPb, have the same domain structures as mammalian $\mathrm{C} 1 \mathrm{r} / \mathrm{C} 1 \mathrm{~s} /$ MASP-1/MASP-2 (Nonaka et al., 1999), and both of C1r, $\mathrm{C} 1 \mathrm{~s}$, MASP-1, and MASP-2 them are more similar to mammalian MASP-1 than to mammalian C1r/C1s/MASP-2 (Xin et al., 1997). Ascidian body fluid contains opsonic activity that enhances the phagocytosis of yeast by ascidian hemocytes, which indicates that the lectin-dependent opsonic complement system, and the alternative-like pathway existed prior to the emergence of the vertebrates and well before the establishment of acquired immunity (Nonaka and Azumi, 1999). The presence of C1q in Ciona was unexpected, since mammalian C1q binds to immunoglobulins (Dodds 2002). However, human C1q also interacts with $\mathrm{C}$-reactive protein (CRP), an acute phase proteins, and is a member of the pentaxin family, which is also found in horseshoe crab hemolymph plasma (Iwaki et al., 1999). Since Ciona possess pentaxins (Table 4B), a pentaxin may have been the original partner of $\mathrm{C} 1 \mathrm{q}$. Interestingly, both $\mathrm{C} 1 \mathrm{q}$ and pentaxin occur only in a deuterostome or chordate lineage (Fujita, 2002). In addition to the above complement components, many other genes involved in the innate immune system of the invertebrate chordate, Ciona intestinalis, have been identified, including three Toll-like receptors and the genes involved in the intracellular signal transduction of immuno responses, such as MyD88, IL-1 receptor-associated kinase (IRAK), TNF receptor-associated factor (TRAF), NFkB, and IkB. The Ciona genome also contains three IL-1 receptor-like genes (IL-1R), one tumor necrosis factor gene (TNF), and three TNF-receptor-like genes (Azumi et al., 2003). With respect to protein molecules involved in phagocytosis and pathogen recognition, the Ciona genome contains several $\alpha$ and $\beta$ integrins, C-type lectins, scavenger receptor-like protein, Gram-negative bacteria binding protein, and LPS-binding protein (Table 4B). However, no report has been issued on the ascidian hemolymph clotting system.

On the other hand, it is known that $H$. roretzi hemolymph contains several lectins, including a galactose, $N$-acetylglucosamine, and $\mathrm{N}$-acetylgalactosamine-specific lectins, and LPS-binding hemagglutinin, all of which are involved in internal defense mechanisms (Table 4A). Purified galactose-specific lectin, which is present in large amounts in $H$. roretzi hemolymph plasma, strongly enhances the phagocytosis of sheep erythrocytes by $H$. roretzi hemocytes, which suggests that it is a candidate opsonin. Moreover, it is interesting that galactose-specific lectin induces active oxygen $\left(\mathrm{O}_{2}^{-}\right)$production by mammalian leucocytes (Azumi et al., 2000). H. roretzi hemocytes produce $\mathrm{O}_{2}^{-}$ in response to treatment with zymosan, thus, indicating that galactose-specific lectin regulates several cellular reactions in the host defense system (Vasta et al., 1999). Moreover, a search and analysis of immunity-related genes in Ciona suggested the presence of a well and uniquely developed innate immune system in urochordates. In particular, the urochordata genome is expected to provide information on the ancestral state prior to the two rounds of complete genome duplication that are known to have occurred at the early stage of vertebrate evolution (Ohno, 1994). In addition to the horseshoe crabs, freshwater crayfish and ascidians mentioned above, a number of defense molecules that include antimicrobial substances, lectins, $(1 \rightarrow 3)-\beta$-D-glucan, and LPS-binding proteins, Toll-like receptors, cell adhesion proteins, complement-like thioester containing proteins, and proteinase inhibitors have been isolated from many other invertebrates and characterized biochemically (Inamori et al., 2000; Inamori et al., 2004). As it is not our intention to introduce these molecules here, instead we cite the following reviews: Earthworm (Cooper et al., 2003), Sea urchins (Smith, 1999), the Echinoderm Cucumaria frondosa, (Beauegard, et al., 2001), Crustaceans (Smith and Chisholm, 2001), and Molluscs (Loker and Bayne, 1999).

\section{The immune responses of insects}

In the case of insects, the first-line defense barriers are; the outer exoskeleton, the peritrophic matrix of the midgut 
Table 5. Defense molecules found in insects

\begin{tabular}{|c|c|c|}
\hline Protein and peptide & Mass (kDa) & Function \\
\hline \multicolumn{3}{|c|}{ (A) Drosophila melanogaster } \\
\hline Necortic & 48 & serine proteinase inhibitor \\
\hline Persephone & 40 & serine proteinase \\
\hline Spatzle & 27 & cytokine-like function \\
\hline PGRP-SA & 20 & pattern recognition protein \\
\hline GNBP & 49 & pattern recognition protein \\
\hline Toll & 110 & leucine-rich repeat (LRR) protein \\
\hline Myd-88 & 54 & adaptor protein \\
\hline Tube & 46 & adaptor protein \\
\hline Cactus & 50 & ankyrin repeats mediate protein \\
\hline Dorsal & 67 & transcription factor \\
\hline Dif & 67 & transcription factor \\
\hline PGRP-LC & 50 & d-pathway receptor (PGRP domain) \\
\hline IMD & 67 & Zn-finger domain containing protein \\
\hline Fadd & 48 & caspase8-like apoptosis regulator \\
\hline TAK1 & 68 & serine/threonine protein kinases \\
\hline IRD5 & 75 & serine/threonine protein kinases \\
\hline DREDD & 31 & death related ced-3 like protein \\
\hline Relish & 97 & transcription factor \\
\hline \multicolumn{3}{|l|}{ (B) Sarcophaga peregrina } \\
\hline Sarcotoxin I & 3.5 & antibacterial peptide \\
\hline Sarcotoxin II & 24 & antibacterial peptide \\
\hline Sarcotoxin III & 7 & antibacterial peptide \\
\hline Sapecin & 4 & antibacterial peptide \\
\hline 5-S-GAD & 0.573 & antibacterial molecule \\
\hline AFP & 7 & antifungal peptide \\
\hline Sarcophaga lectin & $32 / 30$ & galactose-binding lectin \\
\hline Granuloctin & 20 & mucin-binding lectin \\
\hline $26 / 29 \mathrm{kDa}$ protease & $26 / 29$ & cathepsin-like protease \\
\hline
\end{tabular}

PGRP-SA, peptidoglycan recognition protein-short form A; GNBP-1, Gram-negative binding protein-1; Myd88, myeloid differentiation primary-response protein 88; Dif, dorsal-related immunity factor; PGRP-LC, peptidoglycan recognition protein-long form C; IMD, immune deficiency; Fadd, Fas-associated death domain; Tak1; transforming-growth-factor- $\beta$-activated kinase1; IRD5, immune response E deficient 5; RIP, receptor-interacting protein; DREDD, death-related ced-3/Nedd2-like protein; AFP, antifungal protein; 5-S-GAD, $N$ $\beta$-alanyl-5-S-glutathionyl-dopa.

epithelium, and the chitinous lining of the trachea. But, these physical barriers cannot prevent penetrations by pathogenic microbes. Once microbes have entered the haemocoel, they are exposed to humoral and cellular responses (Leclerc and Reichhart, 2004; Waterfield et al., 2004; Abraham and Jacobs-Lorena, 2004). Humoral defenses include the production of antimicrobial peptides, the induction of lectin synthesis, and the activation of the pro-PO system, whereas cellular defenses involve hemocyte-mediated immune responses, which include phagocytosis and encapsulation. The differentiation of humoral and cellular defenses is not distinct as many humoral factors affect hemocyte function. Studies regarding insect defense reactions in different insect models have identified several important defense molecules that sense invading microorganisms. Although most studies of humoral and cellular reactions have been performed in large-bodied insects such as $S$. perigrina (Fig. 2E), B. mori (Fig. 2F), M. sexta (Fig. 2G), T. molitor (Fig. 2H-1), and H. diomphalia larvae (Fig. 2H-2), excellent genetic and molecular level investigations have been performed in D. melanogaster (Fig. 2D). Table 5 summarizes the various defense molecules found in insects. Our knowledge of innate immunity in insects and mammals has increased dramatically (Hoffmann, 2003; Iwasaki and Medzhitov, 2004). The recruitment of a similar pattern of recognition receptors and pathways in insects and mammals to stave off infection suggests that they have developed similar mechanism and molecular pathways to recognize and eliminate pathogenic invaders. Figure 2 (D-H) shows insects that have been used as model systems by studies on insect innate immunity. Here we summarize the innate immune-related molecules in insects. 
Table 5. Continued

\begin{tabular}{|c|c|c|}
\hline Protein and peptide & Mass (kDa) & Function \\
\hline \multicolumn{3}{|c|}{ (C) Bombyx mori and Manduca sexta } \\
\hline \multicolumn{3}{|c|}{ B. mori } \\
\hline pro-PO & 70 & melanin synthesis \\
\hline Bombyx PGRP & 20 & PGN recognition protein \\
\hline Bombyx $\beta$ GRP & 50 & $\beta$-1,3-glucan recognition protein \\
\hline PPAE & 40 & pro-PO activating enzyme \\
\hline \multicolumn{3}{|l|}{ M. sexta } \\
\hline Immulectin-4 & 32 & encapsulation and melanization enhancer \\
\hline Immulectin-3 & 33 & LPS-specific lectin \\
\hline Manduca $\beta$ GRP & 50 & $\beta$-1,3-glucan recognition protein \\
\hline serpin & 40 & serine protease inhibitor \\
\hline plasmocyte-spreading & 13 & paralytic peptide \\
\hline \multicolumn{3}{|l|}{ peptide } \\
\hline PPAE & 40 & pro-Po activating enzyme \\
\hline pro-PO & 70 & melanin synthesis \\
\hline \multicolumn{3}{|c|}{ (D) Holotrichia diomphalia and Tenebrio molitor } \\
\hline Holotricin-1 & 40 & antibacterial peptide \\
\hline Tenecin-1 & 40 & antibacterial peptide \\
\hline Holotricin-2 & 65 & antibacterial peptide \\
\hline Tenecin 2 & 65 & antibacterial peptide \\
\hline Holotricin-3 & 75 & antifungal peptide \\
\hline Tenecin-3 & 75 & antifungal peptide \\
\hline Tenebrio $\beta$ GRP & 45 & $\beta$-1,3-glucan recognition protein \\
\hline Holotrichia PGRP-1 & 20 & pattern recognition protein \\
\hline Holotrichia PGRP-2 & 18 & pattern recognition protein \\
\hline $75 \mathrm{kDa}$ protein & 75 & encapsulation-related protein \\
\hline PPAF-I & 35 & easter-type serine protease \\
\hline PPAF-II & 45 & masquerade-type serine protease \\
\hline PPAF-III & 35 & easter-type serine protease \\
\hline Holotrichia pro-PO & 70 & melanin synthesis \\
\hline Tenebrio pro-PO & 70 & melanin synthesis \\
\hline Calreticulin & 40 & encapsulation protein \\
\hline
\end{tabular}

pro-PO, pro-phenoloxidase; PPAE, pro-PO activating enzyme; PPAF, pro-phenoloxidase activating factor; $\beta$ GRP, $\beta$-1,3-glucan recognition protein.

Drosophila (D) melanogaster. Two important pattern recognition receptors, Toll and PGN recognition protein-LC (PGRP-LC), which sense microbial infection upstream of the Toll pathway (activated mainly by fungi and Gram-positive bacteria) and the immune deficiency (IMD) pathway (activated mainly by Gram-negative bacteria), respectively, have been found. Figure 7 shows two main signaling pathways that regulate the expressions of the antimicrobial genes of Drosophila, which have been extensively reviewed recently (Gobert et al., 2003; Brennan et al., 2004; Hultmark, 2003). Activation of the Toll receptor by its ligand spätzle leads to the formation of a multimeric receptor-adaptor complex, which comprises three death-domain proteins: MyD88, Tube, and the kinase Pelle. The assembly of these proteins into a complex induces phosphorylation of Ik-B-like inhibitor Cactus (by an unknown kinase distinct from Pelle). Phosphorylated cactus is degraded by proteasomes and dissociates from Rel transcription factor dorsal-related immunity-factor (DIF), which is then free to translocate into the nucleus and activate numerous antimicrobial genes of Drosophila. The IMD pathway is probably triggered by an interaction between the transmembrane receptor PGRP-LC and peptidoglycan from Gram-negative bacteria [diaminopimelate (DAP)-type peptidoglycan]. The activation of this pathway triggers a cascade of kinases (DmTAK), which ultimately phosphorylate the Rel protein Relish. Phosphorylated Relish is then cleaved by DREDD caspase to remove the Ik-B like domain from the Rel DNA binding domain. Ik-B can then translocate into the nucleus, where it 


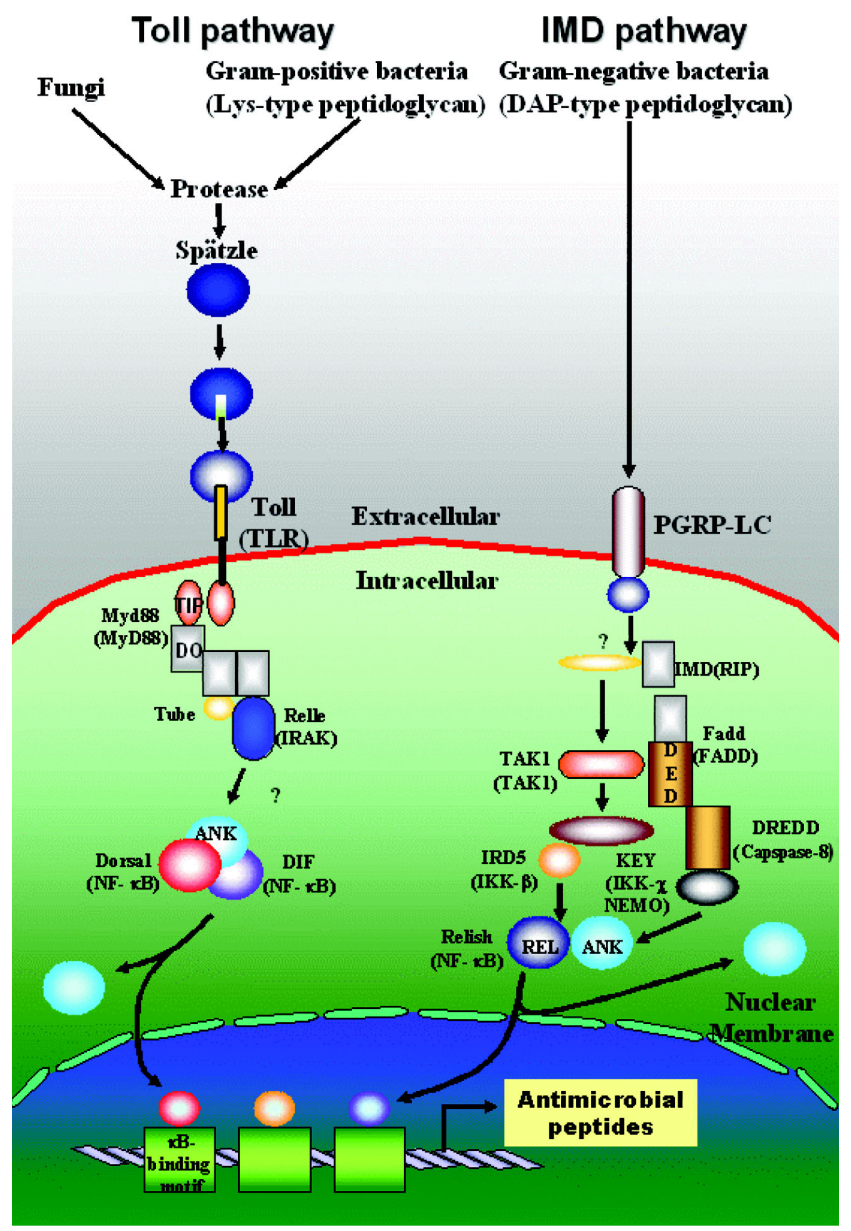

Fig. 7. The Toll and IMD pathways of Drosophila system.

regulates the transcription of immune related genes. These two pathways represent a typical paradigm of innate immuneresponse regulation in Drosophila, and demonstrate how two distinct signaling cascades can modulate the expression of a complex transcriptional programme in response to different pathogenic microbes.

Moreover, the antifungal peptide gene, Drosomycin, is predominantly activated by the Toll pathway in response to fungal and some Gram-positive bacteria infections. However, the antibacterial peptide gene, Dipertericin, is mainly activated by the IMD pathway in response to Gram-negative or some Gram-positive bacterial infections. Also, the Toll and IMD pathways share similarities with the interleukin-1 (IL-1/ TLR and Tumor Necrosis Factor- (TNF- $\alpha$ ) pathway that regulates NF-kB in mammals. The concept of the conservation of immune response in insects and mammals is now invigorating the field of innate immunity. In particular, the discovery of human Toll-like receptor (TLR) represented a turning point in the study of the mammalian immune system and opened many new research possibilities, which supports the notion that Drosophila presents a good model for the analysis of immune-response pathways.
The identification of PGRPs as pattern recognition receptors upstream of the Toll and IMD pathways, have raised the following pivotal questions. How can the bacterial sensing specificities of PGRPs be explained at the molecular level? and, How do PGRPs send signals downstream? Recently, the first crystal structure of Drosophila PGRP-LB was reported (Kim et al., 2003). This structure demonstrates that this catalytic PGRP contains an active site cleft with a zinc cage, and that surface residues at the cleft are poorly conserved, thus indicating that PGRPs show widely varying individual specificities for molecular patterns on microbial cell walls. Behind this cleft, the presence of a distinctive hydrophobic groove suggested that the opposite face of PGRP subserves subsequent signaling after PGRP binding to the polymeric bacterial cell wall.

Sarcophaga (S) peregrina. Natori and his colleagues concentrated on this insect model and have isolated numerous antibacterial peptides, humoral lectins, and antifungal protein from fleshfly, S. peregrina, larvae. They studied the involvements of these proteins in self-defense and development, especially in metamorphosis (Natori et al., 1999), and their findings suggest that immunity and development are deeply related. Recently, they isolated two novel antimicrobial molecules, named 5-S-GAD and KLKLLLLLKLK- $\mathrm{NH}_{2}$ (Leem et al., 1996; Nakajima et al., 1997). The former has the $N$ - $\beta$-alanyl5-S-glutathionyl-dopa structure (Fig. 8), and is produced in response to bacterial infection. Interestingly, this molecule has shown novel anti-tumor activity against a human breast cancer cell line (MDA-MB-4355), indicating that 5-S-GAD has a cytotoxicity associated with the generation of hydrogen peroxide $\left(\left(\mathrm{H}_{2} \mathrm{O}_{2}\right)\right.$ and superoxide $\left(\mathrm{O}_{2}^{-}\right)$. They suggested that 5$S$-GAD inhibits tyrosine kinase (important for tumor cell growth), because src-kinase phosphorylation was impaired by 5-S-GAD in vitro (Hori et al., 1997). A novel synthetic antibacterial peptide KLKLLLLLKLK- $\mathrm{NH}_{2}$ derived from the Sarcophaga antibacterial peptide Sapecin, showed significant chemotherapeutic activity in methicillin-resistant Staphylococcus aureus-infected mice and an ability to produce superoxide $\left[\mathrm{O}_{2}^{-}\right]$anion after human neutrophil activation (Cho et al., 1999). These results provide us with the opportunity to develop new chemotherapeutic agents from insect defense molecules.

Bombyx (B) mori and Manduca (M) sexta. Insect pathologists have observed melanized capsules and nodules around hypae invaded by fungi and bacteria, and have suggested that the synthesis of melanin pigment is triggered by fungi or bacteria. Several groups have shown that melanin is synthesized by phenoloxidase (PO), and that $\mathrm{PO}$ is present as an inactive precursor, pro-PO, in hemolymph. Also, in addition to their vital role in innate immunity, the POs of insects are important for the pigmentation and sclerotization of many insect tissues (Sugumaran, 2002; Tzou et al., 2002). It was suggested that the activation of pro-PO is caused by the pro-PO activating 


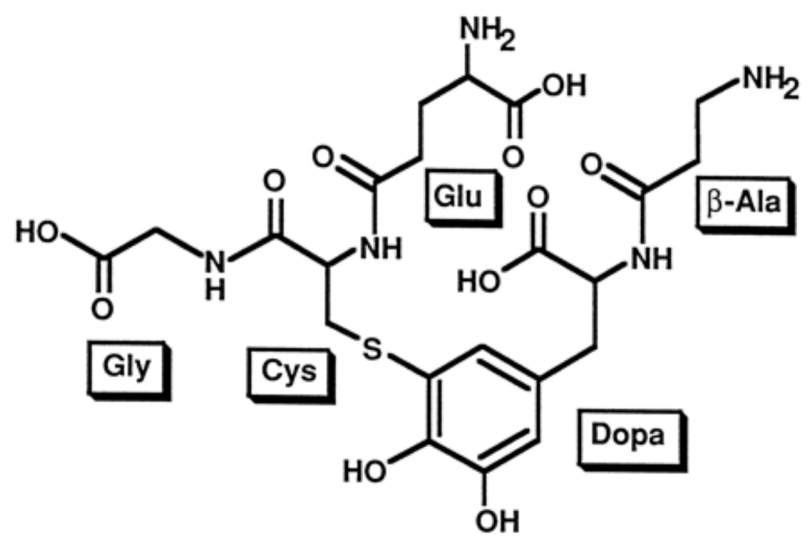

Fig. 8. The structure of 5-S-GAD.

system (or the pro-PO system) that involves; pattern recognition proteins capable of binding to pathogenic patterns, proteases that become active in the presence of microbial patterns; and other factors with the abilities to regulate the system, e.g. protease inhibitors. However, the elucidation of the activation mechanism of the insect pro-PO system is hampered by the fact that pro-PO is spontaneously activated when hemolymph is collected via an integumental incision. B. mori (silkworm) and $M$. sexta (tobacco hornworm) have proven to be good model systems for studying pro-PO activation system, because they may be obtained in large amounts of the hemolymphs from these insects.

Several important innate-immune-related proteins of the Bombyx pro-PO system have been purified and characterized by Ashida and colleagues. In particular, silkworm PGRP and $\beta$-1,3-glucan binding protein (bGRP) were first purified from hemolymph and identified as peptidoglycan and $\beta$-1,3-glucan pattern recognition proteins, respectively (Yoshida et al., 1996; Ochiai and Ashida, 1988). These proteins are also known to induce the activation of the pro-PO system in vitro. Bombyx PGRP is a $19 \mathrm{kDa}$ protein and was named because of its selective affinity for Gram-positive bacterial peptidoglycan. It was demonstrated that the binding of purified PGRP required a peptidoglycan with a glycan portion larger than at least two or more repeating units. In addition, PGRP bound peptidoglycan had no detectable amidase activity. The study of PGRP led to the cloning of PGRP orthologues from other animals, and these studies have revealed that PGRPs form an evolutionarily conserved family of proteins. $\beta \mathrm{GRP}$ was identified in the hemolymph of immuno-challenged silkworms and was found to have a structure similar to that of Gram-negative bacteria binding protein (GNBP) (Lee et al., 1996). Moreover, $\beta$ GRP/GNBP homologues have been isolated from multiple insect species (Fabrick et al., 2004; Ma and Kanost, 2000; Zhang et al., 2003), but are absent from the vertebrate genome, though one orthologue was found in the sea urchin (Bachman and McClay, 1996). The COOH-terminal domain of GNBP/ $\beta$ GRP shares sequence similarity with bacterial $\beta$-1,3-glucanase, and substitutions of the amino acid residues required for its catalytic activity prevented the activation of both of these entities, as is the case for PGRP bound to peptidoglycan. However, it remains unclear how PGRP and bGRP exert their biological effects and activate the next component of the proPO cascade when they bind to microbial triggers.

Regarding the pro-PO system, the Ashida group cloned Bombyx pro-PO, which shows high homology with the copper-binding site sequences of arthropod hemocyanins, and identified the pro-PO cleavage sites targeted by pro-PO activating enzyme (PPAE) (Kawabata et al., 1995). They proposed that the activation mechanism of Bombyx pro-PO system involves PGRP, bGRP, pro-BAEEASE (an uncharacterized enzyme capable of hydrolyzing $N$ - $\alpha$-benzoylarginine-ethyl ester), pro-PPAE (Drosophila easter type-serine protease) and two pro-POs. However, the relationships between these factors and pro-POs remain unknown at the molecular level (Ashida and Brey, 1998).

The Kanost group cloned immulectin (32 kDa), a C-type lectin, from an M. sexta larval fat body cDNA library. Protein synthesis of immulectin was induced by injecting killed yeast or Gram-positive or Gram-negative bacteria, and its mRNA was induced in fat bodies by injecting bacteria ( $\mathrm{Yu}$ et al., 1999; Kanost et al., 2004). Immulectin contains two carbohydrate recognition domains (CRDs). The $\mathrm{COOH}$-terminal CRD most resembles that of LPS binding protein (Jomori and Natori, 1991) from the American cockroach (Periplaneta americana) and shares $26-35 \%$ identity with the CRDs of various mammalian C-type lectins (Ezekowitz et al., 1988). Recombinant immulectin agglutinated yeast and Gram-negative bacteria. Interestingly, a combination of immulectin and E. coli LPS activated PO more rapidly than immulectin alone, whereas LPS alone had little effect on PO activation, indicating that immulectin synthesized in response to bacterial or fungal infections may help trigger a protective response in $M$. sexta in a manner resembling that of mannose-binding lectin, a $\mathrm{C}$ type lectin that functions in the mammalian innate immune system. Also, the Kanost group published details of the characterization and functional analysis of 12 naturally occurring reactive site serpin variants from $M$. sexta. They found that 12 serpin variants were produced from a single gene during an analysis of more than 50 serpin cDNAs of $M$. sexta (Kanost, 1999). The $\mathrm{NH}_{2}$-terminal 336 residues of these serpins were identical and they differed only at $\mathrm{COOH}-$ terminal 39-46 residues. One of the serpin variants, serpin-1J, strongly inhibited the activation of $M$. sexta $\mathrm{PO}$, suggesting that serpin-1J may be an important regulator of endogenous serine protease(s), which are involved components of insect defense response to microbial infection (Jiang and Kanost, 1997).

Holotrichia $(\mathrm{H})$ diomphalia and Tenebrio $(\mathrm{T})$ molitor. One of the authors of the present review studied the antimicrobial proteins of two coleopteran insects. To date six groups of proteins have been purified and characterized, namely, 


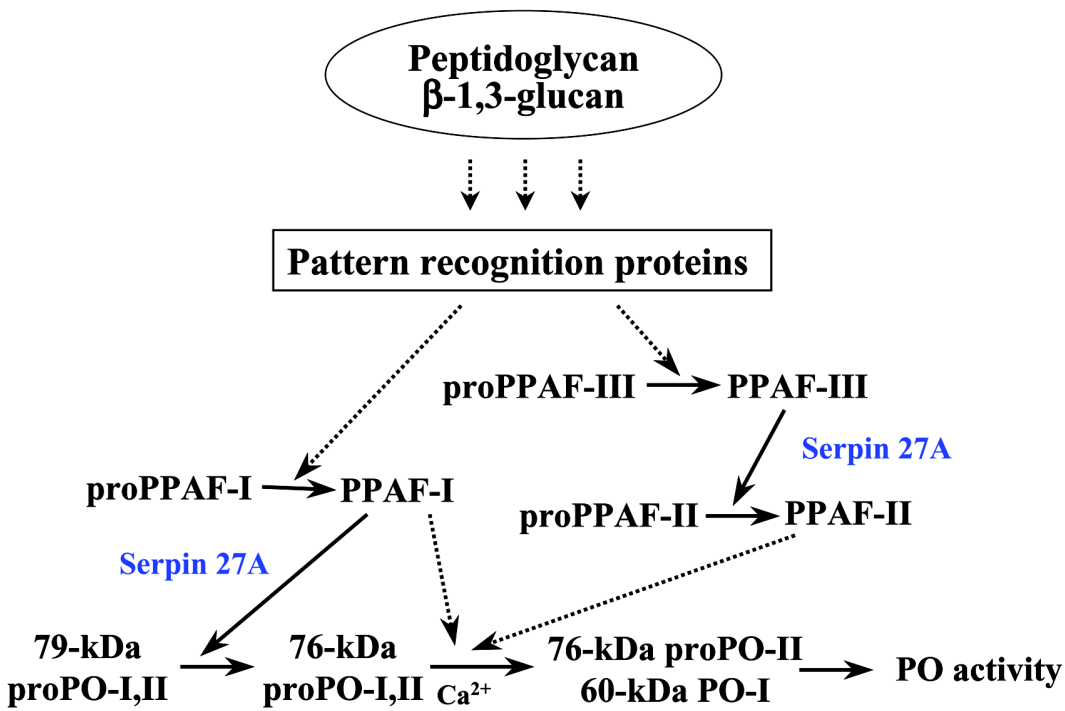

Fig. 9. Downstream part of pro-PO activation in $H$. diomphalia larvae.

Holotricin 1, 2, and 3, and Tenecin 1, 2, and 3. The antibacterial proteins, Holotricin 1 and 2, and Tenecin 1 and 2 are not normally present, but are promptly synthesized by the fat bodies and hemocytes and secreted into hemolymph when insects are in the acute phase of infection. Holotricin 1 and Tenecin 1 are a group of defensin or sapecin type antibacterial proteins and are more effective against Gram-positive bacteria. These proteins consist of 43 amino acids, which include six cysteine residues that form three intramolecular disulfide linkages (Moon et al., 1994; Lee et al., 1995a). Holotricin 2 and Tenecin 2 are beetle-specific antibacterial proteins that show potent bactericidal activity against Gramnegative bacteria. These proteins consist of 72 amino acid residues with no cysteine residues (Lee et al., 1994). Holotricin 3 and Tenecin 3 are novel Gly- and His-rich proteins that consist of 84 amino acid residues and show significant activity against Candida albicans (Lee et al., 1995b; Lee et al., 1996). These proteins have no effects on the viabilities of Gram-positive or Gram-negative bacteria, but ionic condition seems to influence the antifungal activity of Tenecin 3. The obvious difference between Holotricin 3 and Holotricin 1 or 2 is that Holotricin 3 is a constitutively expressed protein of hemolymph, whereas Holotricin 1 and 2 are inducible.

The insect pro-PO system consists of two parts. The first of which is the recognition reaction between invading pathogens and pattern recognition proteins, and the second a signal triggered by pathogen invasion to down-stream pro-PO activating factor(s). The nature of the linkage between the upand down-stream portions of the pro-PO system is unknown at the molecular level. Recently, we characterized three proPO activating factors (PPAF-I, -II and III) and two pro-POs (pro-PO-I and II), which are necessary for the activation of coleopteran $H$. diomphalia larvae. The overall structure of the $37 \mathrm{kDa}$ pro-PPAF-I is almost identical to that of Drosophila easter, a serine protease essential for pattern formation during embryonic development. The mass of pro-PPAF-II (45 kDa) is similar to that of Drosophila masquerade, a non-proteolytic serine protease-like protein with a mutation in the catalytic triad (Lee et al., 1998; Kwon et al., 2000; Kim et al., 2002). In addition, the structure of pro-PPAF-III is similar to that of easter serine protease, which can cleave $55 \mathrm{kDa}$ pro-PPAF-II to generate $45 \mathrm{kDa}$ PPAF-II. Furthermore, pro-PO-I and proPO-II (both $79-\mathrm{kDa}$ ) have been characterized in Holotrichia, and their structural changes during activation have been examined using in vitro reconstitution experiments. When these pro-POs were incubated with PPAF-I, both were converted to 76-kDa pro-POs, which did not exhibit any PO activity. However, when pro-PO-I or pro-PO-II were incubated with PPAF-I, pro-PPAF-II, or PPAF-III in the presence of $\mathrm{Ca}^{2+}$, new bands of a $60-\mathrm{kDa}$ PO-I (with PO activity) and of a 76-kDa pro-PO-II were detected. These results indicate that the conversions of Holotrichia pro-POs to their active forms with PO activity are accomplished by PPAF-I, PPAF-II, and PPAF-III through a two-step limited proteolysis in the presence of $\mathrm{Ca}^{2+}$. As shown in Fig. 9, these detailed studies provided data for the first time on the relationship between two different pro-POs and three pro-PO activating factors in a large insect. Also, two pattern recognition proteins, Holotrichia PGRP and Tenebrio $\beta-1,3-$ glucan-recognition protein, have been identified in two coleopteran insects (Zhang et al., 2003; Lee et al., 2004). Both proteins are involved in the activation of $\beta$-1,3-glucan dependent pro-PO activation. Interestingly, these pattern recognition proteins were specifically degraded following the activation of pro-PO with $\beta$-1,3-glucan and calcium ions. We proposed that this degradation pattern of recognition proteins is an important regulator of insect pro-PO system activation. However, it remains to be determined how the connection between the upstream and downstream portions of the pro-PO 
cascade is organized and activated at the molecular level.

\section{Conclusion}

During the last two decades, much progress has been made in the understanding of the invertebrate innate immune system. These studies at the cellular, biochemical, and genetic levels have led to discoveries of novel defense reactions and protein molecules, and also of new effector pathway mechanisms elicited after the recognition of "nonself". These results have provided new insights of the roles of host defense molecules and have resulted in the adoption of new invertebrate immunology concepts. This review summarizes the present status of invertebrate innate immune systems, by focusing on the molecular structures and functions of various defense components identified in invertebrate hemolymph and tissues. The data collected here indicate that individual species have characteristic patterns of host defense that depend on a wide variety of biological responses. Even in Arthropods, large differences in host defense systems are apparent between insects, the horseshoe crab, and the freshwater crayfish. For instance, insects and crayfish utilize a strong prophenoloxidase activating system as a biosensor that can react with various epitopes, such as LPS, peptidoglycan, and $(1 \rightarrow 3)-\beta-D-$ glucan. In contrast, the prophenoloxidase activating system of the horseshoe crab appears to be a less important component of the host defense, but provides a strong LPS / $(1 \rightarrow 3)-\beta$-Dglucan sensitive hemolymph clotting system, which seems to be important for the encapsulation and elimination of invaders, and to be linked with phagocytosis. On the other hand, the ascidians have a sophisticated lectin-complement system that occupies a pivotal role in host defense. Further understanding of innate immune systems from the comparative biochemical and genetic points of view, and careful evaluations of their homologous characters will undoubtedly provide an overview of ancestral defense mechanisms.

\section{Added in Proof}

Quite recently, Zhu et al. (2005) reported that a functional homolog of vertebrate complement of $\mathrm{C} 3$ was isolated from the horseshoe crab, Carcinos rpius rotundicauda. This C3 resembles human $\mathrm{C} 3$ and shows closest homology to $\mathrm{C} 3$ sequences of lower deuterostomes, Additionally, they identified the complement $\mathrm{C} 2 / \mathrm{Bf}$, a homolog of vertebrate $\mathrm{C} 2$ and factor $\mathrm{B}(\mathrm{Bf})$ that participates in $\mathrm{C} 3$ activation. Thus, a primitive yet complex opsonic complement defense system is revealed in the horseshoe crab, a protostome species.

Acknowledgments We thank Drs. K. Söderhäll, K, Azumi. S. Kurata and T. Numakunai for providing the crayfish and ascidian photographs, and for their helpful comments concerning Tables 3 and 4. In addition, we thank Drs. T.
Ozaki, S. Kawabata, J. Mizuguchi and Mrs. M. Katsuo for their help with the figures and tables.

\section{References}

Abraham, E. G. and Jacobs-Lorena, M. (2004) Mosquito midgut barriers to malaria parasite development. Insect Biochem. Mol. Biol. 34, 667-671.

Aderem, A. and Ulevitch, R. (2000) Toll-like receptors in the induction of the innate immune response. Nature 406, 782-787.

Agarwara, K. L., Kawabata, S., Hirata, M., Miyagi, M., Tsunasawa, S. and Iwanaga, S. (1996) Cysteine protease inhibitor stored in the large granules of horseshoe crab hemocytes: Purification, characterization, cDNA cloning and tissue localization. $J$. Biochem. (Tokyo), 119, 85-94.

Agarwara, K. L., Kawabata, S., Miura, Y., Kuroki, Y. and Iwanaga, S. (1996) Limulus intracellular coagulation inhibitor type 3. Purification, characterization, cDNA cloning, and tissue localization. J. Biol. Chem. 271, 23768-23774.

Ariki, S., Koori, K., Osaki, T., Motoyama, K., Inamori, K. and Kawabata, S. (2004) A serine protease zymogen functions as a pattern-recognition receptor for lipopolysaccharides. Proc. Natl. Acad. Sci. USA 101, 953-958.

Armstrong, P. B. (2001) The contribution of proteinase inhibitors to immune defense. Trends Immunol. 22, 47-52.

Ashida, M. and Brey, P. T. (1998) Recent advances in research on the insect prophenoloxidase cascade; in Molecular Mechanisms of Immune Responses in Insects, Brey, P. T. and Hultmark, D. (eds.), pp. 135-172, Chapman \& Hall, New York, USA

Azumi, K., Ishimoto, R., Fujita, T., Nonaka, M. and Yokosawa, H. (2000) Opsonin-independent and -dependent phagocytosis in the ascidian Halocynthia: galactose-specific lectin and complement C3 function as target-dependent opsonins. Zoological Sci. 17, 625-632.

Azumi, K., Santis, R., Tomaso, A., Rigoutsos, I., Yoshizaki, F., Pinto, M. R., Marino, R., Shida, K., Ikeda, M., Ikeda, M., Arai, M., Inoue, Y., Shimizu, T., Satoh, N., Rokhsar, D. S., Pasquier, L. D., Kasahara, M., Satake, M. and Nonaka, M. (2003) Genomic analysis of immunity in a Urochordate and the emergence of the vertebrate immune system: "waiting for Godot”. Immunogenetics. 55, 570-581.

Bachman E. S. and McClay, D. R. (1996) Molecular cloning of the first metazoan beta-1,3 glucanase from eggs of the sea urchin Strongylocentrotus purpuratus. Proc. Natl. Acad. Sci USA 93, 6808-6813.

Bang, F. B. (1956) A bacterial disease of Limulus polyphemus. Bull. Johns Hopkins Hosp. 98, 325-351.

Beauregard, K. A., Truong, N. T., Zhang, H., Lin, W. and Beck, G. (2001) The detection and isolation of a novel antimicrobial peptide from the echinoderm, Cucumaria frondosa. Adv. Exp. Med. Biol. 484, 55-62.

Begum, N., Matsumoto, M., Tsuji, S., Toyoshima, K. and Seya, T. (2000) The primary host defense system across humans, flies and plants. Current Trends in Immunology, 3, 59-74.

Beisel, H. G., Kawabata, S., Iwanaga, S., Huber, R. and Bode, W. (1999) Tachylectin-2: crystal structure of a specific GlcNAc/ GalNAc binding lectin involved in the innate immunity host defense of the Japanese horseshoe crab Tachypleus tridentatus. EMBO. J. 18, 2313-2322.

Bergner, A., Muta, T., Iwanaga, S., Beisel, H. G., Delotto, R. and 
Bode, W. (1997) Horseshoe crab coagulogen is an invertebrate protein with a nerve growth factor-like domain. Biol. Chem. 378, 283-287.

Bergner, A., Oganessyan, V., Muta, T., Iwanaga, S., Typke, D., Huber, R. and Bode, W. (1996) Crystral structure of a coagulogen, the clotting protein from horseshoe crab: a structural homologue of nerve growth factor. EMBO J. 15, 6789-6797.

Bogdan, C., Röllinghoff, M. and Diefenbach, A. (2000) Reactive oxygen and reactive nitrogen intermediates in innate and specific immunity. Curr. Opin. Immunol. 12, 64-76.

Brennan, C. A. and Anderson, K. V. (2004) Drosophila: the genetics of innate immune recognition and response. Annu. Rev. Immunol. 22, 457-483.

Cannon, J. P., Haire, R. N., Rast, J. P. and Litman, G. W. (2004) The phylogenetic origins of the antigen-binding receptors and somatic diversification mechanisms. Immunol. Rev. 200, 12-22.

Caroll, M. (2004) The complement system in regulation of adaptive immunity. Nature immunology, 5, 981-986.

Cerenius, L., Bangyeekhun, E., Keyser, P., Söderhäll, I. and Söderhäll, K. (2003) Host prophenoloxidase expression in freshwater crayfish is linked to increased resistance to the crayfish plaque fungus, Aphanomyces astaci. Cell. Microbiol. 5, 353-357.

Cerenius, L., Liang, Z., Duvic, B., Keyser, P., Hellman, U., Palva, T., Iwanaga, S. and Söderhäll, K. (1994) Structure and biological activity of a 1,3- $\beta$-D-glucan-binding protein in crustacean blood. J. Biol. Chem. 269, $29462-29467$.

Cerenius, L. and Söderhäll, K. (2002) Early events in crustacean innate immunity. Fish Shellfish Immunology 12, 421-437.

Chiou, S. T., Chen, Y. W., Chen, S. C., Chao, C. F. and Liu, T. Y. (2000) Isolation and characterization of proteins that bind to galactose, lipopolysaccharide of Escherichia coli, and protein A of Staphylococcus aureus from the hemolymph of Tachypleus tridentatus. J. Biol. Chem. 275, 1630-1634.

Cho, J. H., Homma, K., Kanegasaki, S. and Natori, S. (1999) Activation of human neutrophils by a synthetic anti-microbial peptide, KLKLLLLLKLK-NH ${ }_{2}$, via cell surface calreticulin. Eur. J. Biochem. 266, 878-885.

Cooper, E. L., Kauschke, E. and Cossarizza, A. (2002) Digging for innate immunity since Darwin and Metchnikoff. BioEssays 24, 319-333.

Crouch, E., Hatshorn, K. and Ofek, I. (2000) Collections and pulmonary innate immunity. Imm. Rev. 173, 52-56.

Decker, H. and Tuczek, F. (2000) Tyrosinase/catecholoxidase activity of hemocyanins: Structural basis and molecular mechanism. Trends Biochem. Sci. 25, 392-397.

Dodds, A. W. (2002) Which come first, the lectin/classical pathway or the alternative pathway of complement. Immunobiol. 205, 340-354.

Ezekowitz, R. A. B., Day, L. E. and Herman, G. A. (1988) A human mannose-binding protein is an acute-phase reactant that shares sequence homology with other vertebrate lectins. J. Exp. Med. 167, 1034-1046.

Fabrick, J. A., Baker, J. E. and Kanost, M. R. (2004) Innate immunity in a pyralid moth: functional evaluation of domains from a beta-1,3-glucan recognition protein. J. Biol. Chem. 279, 26605-26611.

Fujita, T. (2002) Evolution of the lectin-complement pathway and its role in innate immunity. Nat. Rev. Immunol. 2, 346-353.

Fujitani, N., Kawabata, S., Osaki, T., Kumaki, Y., Demura, M., Nitta, K. and Kawano, K. (2002) Structure of the antimicrobial peptide tachystatin A. J. Biol. Chem. 277, 23651-23657.

Fujita, T., Endo, Y. and Nonaka, M. (2004) Primitive complement system--recognition and activation. Mol. Immunol. 41, 103-111.

Gadjeva, M., Thiel, S. and Jensenius, J. C. (2001) The mannanbinding lectin pathway of the innate immune response. Curr. Opin. Immunol. 13, 74-78.

Gobert, V., Gottar, M., Matskevich, A. A., Rutschmann, S., Royet, J., Belvin, M., Hoffmann, J. A. and Ferrandon, D. (2003) Dual activation of the Drosophila toll pathway by two pattern recognition receptors. Science 302, 2126-2130.

Gokudan, S., Muta, T., Tsuda, R., Koori, K., Kawahara, T., Seki, N., Mizunoe, Y., Wai, S. N., Iwanaga, S. and Kawabata, S. (1999) Horseshoe crab acetyl group recognizing lectins involved in innate immunity are structurally related to fibrinogen. Proc. Natl. Acad. Sci. USA 96, 10086-10091.

Greenberg, S. and Grinstein, S. (2002) Phagocytosis and innate immunity. Curr. Opin. Immunol. 14, 136-145.

Hall, M., Heusden, M. C. and Söderhäll, K. (1995) Identification of the major lipoproteins in crayfish hemolymph as proteins involved in immunorecognition and clotting. Biochem. Biophys. Res. Communs. 216, 939-946.

Hall, M., Wang, R., Antwerpen, R., Sottrup-Jensen, L. and Söderhäll, K. (1999) The crayfish plasma clotting protein: a vitellogenin-related protein responsible for clot formation in crustacean blood. Proc. Natl. Acad. Sci. USA 96, 1965-1970.

Hata, S., Azumi, K. and Yokosawa, H. (1998) Ascidian phenoloxidase: its release from hemocytes, isolation, characterization and physiological roles. Comp. Biochem. Physiol. 119, 769-776.

Hoebe, K., Jansen, E. and Beutler, B. (2004) The interface between innate and adaptive immunity. Nat. Immunol. 5, 971974.

Hoess, A., Watson, S., Siber, G. R. and Liddington, R. (1993) Crystal structure of an endotoxin-neutralizing protein from the horseshoe crab, Limulus anti-LPS factor at $1.5 \mathrm{~A}$ resolution. EMBO J. 12, 3351-3356.

Hoffmann, J. A., Kafatos, F. C., Janeway, C. A. Jr. and Ezekowitz, R. A. B. (1999) Phylogenetic perspectives in innate immunity. Science 284, 1313-1318.

Hoffmann, J. A. (2003) The immune response of Drosophila. Nature 426, 33-38.

Hori, S., Kobayashi, A. and Natori, S. (1997) Monoclonal antibodies against pupa-specific surface antigens of Sarcophaga peregrina (flesh fly) hemocytes. Biochem. Biophys. Res. Commun. 236, 497-501.

Huang, T., Wang, H., Lee, S. Y., Johansson, M. W., Söderhäll, K. and Cerenius, L. (2000) A cell adhesion protein from the crayfish Pacifastacus leniusculus, a serine proteinase homologue similar to Drosophila masquerade. J. Biol. Chem. 275, 9996-10001.

Hultmark, D. (2003) Drosophila immunity: paths and patterns. Curr. Opin. Immunol. 15, 12-19.

Husted, L. B., Sorensen, E. S., Armstrong, P. B., Quigley, J. P., Kristensen, L. and Sottrup-Jensen, L. (2002) Localization of carbohydrate attachment sites and disulfide bridges in Limulus $\alpha_{2}$-macroglobulin: Evidence for two forms differing primary in their bait region sequences. J. Biol. Chem. 277, 43698-43706.

Imler, J. L. and Hoffmann, J. A. (2000) Signaling mechanisms in the antimicrobial host defense of Drosophila. Curr. Opin. Microbiol. 3,16-22.

Inamori, K., Ariki, S. and Kawabata, S. (2004) A toll-like receptor in horseshoe crabs. Immunol. Rev. 198, 106-115. 
Inamori, K., Koori, K., Mishima, C., Muta, T. and Kawabata, S. (2000) A horseshoe crab toll-like receptor structurally related to Drosophila Toll. J. Endotoxin. Res. 2000, 6, 397-399.

Inamori, K., Saito, T., Iwaki, D., Nagira, T., Iwanaga, S., Arisaka, F. and Kawabata, S. (1999) A newly identified horseshoe crab lectin with specificity for blood group A antigen recognizes specific $O$-antigens of bacterial lipopolysaccharides. J. Biol. Chem. 274, 3272-3278.

Iwaki, D., Kawabata, S., Miura, Y., Kato, A., Armstrong, P. B., Quigley, J. P., Nielsen, K. L., Dolmer, K., Sottrup-Jensen, L. and Iwanaga, S. (1996) Molecular cloning of limulus alpha 2macroglobulin. Eur. J. Biochem. 242, 822-831.

Iwaki, D., Osaki, T., Mizunoe, Y., Wai, S. N., Iwanaga, S. and Kawabata, S. (1999) Functional and structural diversities of Creactive proteins present in horseshoe crab hemolymph plasma. Eur. J. Biochem. 264, 314-326.

Iwanaga, S. (1993a) Primitive coagulation systems and their message to modem biology. Thromb. Haemost. 70, 48-55.

Iwanaga, S. (1993b) The limulus clotting reaction. Curr. Opin. Immunol. 5, 74-82.

Iwanaga, S., Muta, T., Shigenaga, T., Miura, Y., Seki, N., Saito, T. and Kawabata, S. (1994a) Role of hemocyte-derived granular components in invertebrate defense. Ann. NY Acad. Sci. 712, 102-116.

Iwanaga, S. (2002) The molecular basis of innate immunity in the horseshoe crab. Curr. Opin. Immunol. 14, 87-95.

Iwanaga, S. and Kawabata, S. (1998) Evolution and phylogeny of defense molecules associated with innate immunity in horseshoe crab. Front. Biosci. 3, 973-984.

Iwanaga, S., Kawabata, S. and Muta, T. (1998) New types of clotting factors and defense molecules found in horseshoe crab hemolymph: their structures and functions. J. Biochem. (Tokyo), 123, $1-15$.

Iwanaga, S., Kawabata, S., Miura, Y., Seki, N., Shigenaga, T. and Muta, T. (1994b) Clotting cascade in the immuno response of horseshoe crab; Phylogenetic Perspectives in Immunity: The Insect Host Defense, Hoffmann, J. and Natori, S. (eds.), pp. 79-96, R. G. Landes Co. Biomedical Publishers, Austin, USA.

Iwanaga, S., Morita, T., Harada, T., Niwa, M., Takada, K., Kimura, T. and Sakakibara, S. (1978) Chromogenic substrates for horseshoe crab clotting enzyme. Its application for the assay of bacterial endotoxins. Haemostasis 7, 183-188.

Iwanaga, S., Miyata, T., Tokunaga, F. and Muta, T. (1992) Molecular mechanism of hemolymph clotting system in Limulus. Thrombosis Res. 68, 1-32.

Iwasaki, A. and Medzhitov, R. (2004) Toll-like receptor control of the adaptive immune responses. Nat. Immunol. 5, 987-995.

Jiang, H. and Kanost, M. R. (1997) Characterization and functional analysis of 12 naturally occurring reactive site variants of serpin-1 from Manduca sexta. J. Biol. Chem. 272, 1082-1087.

Johansson, M. W., Keyser, P. and Söderhäll, K. (1994) Purification and cDNA cloning of a four-domain Kazal proteinase inhibitor from crayfish blood cells. Eur. J. Biochem, 223, 389-394.

Johanson, M. W., Lind, M. I., Holmblad, T., Thörnqist, P.-O. and Söderhäll, K. (1995) Peroxinectin, a novel adhesion protein from crayfish blood. Biochem, Biophys. Res. Commun. 216, 1079-1087.

Jomori, T. and Natori, S., (1991) Molecular cloning of cDNA for lipopolysaccharide-binding protein from the haemolymph of the
American cockroach Periplaneta americana. J. Biol. Chem. 266, 1331813323.

Kairies, N., Beisel, H. G., Fuentes-Prior, P., Tsuda, R., Muta, T., Iwanaga, S., Bode, W., Huber, R. and Kawabata, S. (2001) The $2.0 \AA$ crystal structure of tachylectin $5 \mathrm{~A}$ provide evidence for the common origin of the innate immunity and the blood coagulation system. Proc. Natl. Acad. Sci. USA 98, 1351913524.

Kanost, M. R. (1999) Serine proteinase inhibitors in arthropod immunity. Dev. Comp. Immunol. 23, 291-301.

Kanost, M. R., Jiang, H. and Yu, X. Q. (2004) Innate immune responses of a lepidopteran insect, Manduca sexta. Immunol. Rev. 198, 97-105.

Kawabata, S., Beisel, H. G., Huber, R., Bode, W., Gokudan, S., Muta, T., Tsuda, R., Koori, K., Kawahara, T., Seki, N., Mizunoe, Y., Wai, S. N. and Iwanaga, S. (2001) Role of tachylectins in host defense of the Japanese horseshoe crab Tachypleus tridentatus. Adv. Exp. Med. Biol. 484, 195-202.

Kawabata, S. and Iwanaga, S (1999) Role of lectins in the innate immunity of horseshoe crab. Dev. Comp. Immunol. 23, 391400.

Kawabata, S., Muta, T. and Iwanaga, S. (1996) Clotting cascade and defense molecules found in the hemolymph of the horseshoe crab; in New Directions in Invertebrate Immunology, Söderhäll, K., Iwanaga, S. and Vasta, G. (eds.), pp. 255-283, SOS Publication, Fair Haven, USA.

Kawabata, S., Nagayama, R., Hirata, M., Shigenaga, T., Agarwala, K. L., Saito, T., Cho, J., Nakajima, H., Takagi, T. and Iwanaga, S. (1996) Tachycitin, a small granular component in horseshoe crab hemocytes, is an antimicrobial protein with chitin-binding activity. J. Biochem. (Tokyo) 120, 1253-1260.

Kawabata, S., Saeki, K. and Iwanaga, S. (1996) Limulus kexin: a new type of kex2-like endoprotease specifically expressed in hemocytes of the horseshoe crab. FEBS Lett. 386, 201-204.

Kawabata, S., Saito, T., Saeki, K., Okino, N., Mizutani, A., Toh, Y. and Iwanaga, S. (1997) cDNA cloning, tissue distribution, and subcellular localization of horseshoe crab big defensin. Biol. Chem. 378, 289-292.

Kawabata, S., Tokunaga, F., Kugi, Y., Motoyama, S., Miura, Y., Hirata, M. and Iwanaga, S. (1996) Limulus factor D, a 43-kDa protein isolated from horseshoe crab hemocytes, is a serine protease homologue with antimicrobial activity. FEBS Lett. 398, 146-150.

Kawabata, S. and Tsuda, R. (2002) Molecular basis of non-self recognition by the horseshoe crab tachylectins. Biochem. Biophys. Acta, 1572, 414-421.

Kawabata, T., Yasuhara, Y., Ochiai, M., Matsuura, S. and Ashida, M. (1995) Molecular cloning of insect pro-phenoloxidase: a copper-containing protein homologous to arthropod hemocyanin. Proc. Natl. Acad. Sci. USA 92, 7774-7778.

Kawasaki, H., Nose, T., Muta, T., Iwanaga, S., Shimohigashi, Y. and Kawabata, S. (2000) Head-to-tail polymerization of coagulin, a clottable protein of the horseshoe crab. J. Biol. Chem. 275, 35297-35301.

Kenjo, A., Takahashi, M., Matsushita, M., Endo, Y., Nakata, M., Mizuochi, T. and Fujita, T. (2001) Cloning and characterization of novel ficolins from the solitary ascidian, Halocynthia roretzi. J. Biol. Chem. 276, 19959-19965.

Kim, M. S., Baek, M. J., Lee, M. H., Park, J. W., Lee, S. Y., Soderhall, K. and Lee, B. L. (2002) A new easter-type serine 
protease cleaves a masquerade-like protein during prophenoloxidase activation in Holotrichia diomphalia larvae. J. Biol. Chem. 277, 39999-40004

Kim, M. S., Byun, M. and Oh, B.-H. (2003) Crystal structure of peptidoglycan recognition protein LB from Drosophila melanogaster, Nat. Immunol. 4, 787-793.

Krem, M. M. and Cera, E. D. (2002) Evolution of enzyme cascades from embryonic development to blood coagulation. Trends Biochem. Sci. 27, 67-74.

Krutzik, S. R., Sieling, P. A. and Modlin, R. L. (2001) The role of Toll-like receptors in host defense against microbial infection. Curr. Opin. Immunol. 13, 104-108.

Kwon, T. H., Kim, M. S., Choi, H. W., Joo, C. H., Cho, M. Y. and Lee, B. L. (2000) A masquerade-like serine proteinase homologue is necessary for phenoloxidase activity in the coleopteran insect, Holotrichia diomphalia larvae. Eur. J. Biochem. 267, 6188-6196.

Lee, S. Y., Moon, H. J., Kurata, S., Kurama, S., Natori, S. and Lee, B. L. (1994) Purification and molecular cloning of cDNA for an inducible antibacterial protein of larvae of a coleopteran insect, Holotricihia diomphalia. J. Biochem. (Tokyo), 115, 8286.

Lee, S. Y., Moon, H. J., Kawabata, S., Kurata, S., Natori, S. and Lee, B. L. (1995a) A sapecin homologue of Holotrichia diomphalia: Purification, sequencing and determination of disulfide pairs, Biol. Pharm. Bull. 18, 457-459.

Lee, S. Y., Moon, H. J., Kurata, S., Natori, S. and Lee, B. L. (1995b) Purification and cDNA cloning of an antifungal protein from the hemolymph of Holotrichia diomphalia larvae. Biol. Pharm. Bull. 18, 1049-1052.

Lee, S. Y., Cho, M. Y., Hyun, J. H., Lee, K. M., Homma, K. I., Natori, S., Kawabata, S. I., Iwanaga, S. and Lee, B. L. (1998) Molecular cloning of cDNA for pro-phenoloxidase activating factor I, a serine protease is induced by lipopolysaccharide or 1,3-beta-glucan in coleopteran insect, Holotrichia diomphalia larvae. Eur. J. Biochem. 257, 615-621.

Lee, S. Y., Wang, R. and Söderhäll, K. (2000) A lipopolysaccharide and $\beta$-1, 3-glucan binding protein from hemocytes of the freshwater crayfish Pacifastacus leniusculus. Purification, characterization and cDNA cloning. J. Biol. Chem. 275, 1337-1343.

Lee, S. Y. and Söderhäll, K. (2001) Characterization of a pattern recognition protein, a masquerade-like protein, in the freshwater crayfish Pascifastacus leniusculus. J. Immunol. 166, 7319-7326.

Lee, W. J., Lee, J. D., Kravchenko, V. V., Ulevitch, R. J. and Brey, P. T. (1996) Purification and molecular cloning of an inducible gram-negative bacteria-binding protein from the silkworm, Bombyx mori. Proc. Natl. Acad. Sci. USA 93, 78887893.

Lee, Y. J., Chung, T. J., Park, C. W., Hahn, Y. S., Chung, J. H., Lee, B. L., Han, D. M., Jung, Y. H., Kim, S. and Lee, Y. H. (1996) Structure and expression of the tenecin 3 gene in Tenebrio molitor. Biochem. Biophys. Res. Commun. 218, 6-11.

Leclerc, V. and Reichhart, J. M. (2004) The immune response of Drosophila melanogaster. Immunol. Rev. 198, 59-71.

Leem, J. Y., Nishimura, C., Kurata, S., Shimada, I., Kobayashi, A. and Natori, S. (1996) Purification and characterization of $\mathrm{N}$ beta-alanyl-5-S-glutathionyl-3,4-dihydroxyphenylalanine, a novel antibacterial substance of Sarcophaga peregrina (flesh fly). J. Biol. Chem. 271, 13573-13577.
Lemaitre, B., Nicolas, E., Michaut, L., Reichhart, J. M. and Hoffmann, J. A. (1996) The dorsoventral regulatory gene cassette spätzle/Toll/cactus controls the potent antifungal response in Drosophila adults. Cell, 86, 973-983.

Levin, J. and Bang, F. B. (1964) The role of endotoxin in the extracellular coagulation of Limulus blood. Bull. Johns Hopkins Hosp. 115, 265-274.

Liang, Z., Sottrup-Jensen, T., Aspán, A., Hall, M. and Söderhäll, K. (1997) Pacifastin, a novel $155 \mathrm{kDa}$ heterodimeric proteinase inhibitor. Proc. Natl. Acad. Sci. USA 94, 6682-6687.

Lindahl, G., Sjöbring, U. and Johnsson, E. (2000) Human complement regulators: a major target for pathogenic microorganisms. Curr. Opin. Immunol. 12, 44-61.

Loker, E. S. and Bayne, C. J. (1999) Molecular studies of the molluscan response to Digenean infection. Adv. Exp. Med. Biol. 484, 209-222.

Luster, A. D. (2002) The role of chemokines in linking innate and adaptive immunity. Curr. Opin. Immunol. 14, 129-135.

Ma, C. and Kanost, M. R. (2000) A beta1,3-glucan recognition protein from an insect, Manduca sexta, agglutinates microorganisms and activates the phenoloxidase cascade. J. Biol. Chem. 275, $7505-7514$.

Matsushita, M. and Fujita, T. (2001) Ficolins and the lectin complement pathway. Immunol. Rev. 180, 78-85.

Medzhitov, R. and Janeway, C. Jr. (2000) Innate immune recognition: mechanisms and pathways. Immunol. Rev. 173, 8997.

Moon, H. J., Lee, S. Y., Kurata, S., Natori, S. and Lee, B. L. (1994) Purification and molecular cloning of cDNA for an inducible antibacterial protein from larvae of the coleopteran, Tenebrio molitor. J. Biochem. (Tokyo) 116, 53-58.

Morvan, A., Iwanaga, S., Comps, M. and Bachere, E. (1997) In vitro activity of the Limulus antimicrobial peptide tachyplesin I on marine bivalve pathogens. J. Invertebr. Pathol. 69, 177-182.

Muta, T. and Iwanaga, S. (1996a) Clotting and immune defense in Limulidae. Prog. Mol. Subcell. Biol. 15, 154-189.

Muta, T. and Iwanaga, S. (1996b) The role of hemolymph coagulation in innate immunity. Curr. Opin. Immunol. 8, 41-47.

Muta, T., Seki, N., Takaki, Y., Hashimoto, R., Oda, T., Iwanaga, A., Tokunaga, F. and Iwanaga, S. (1995) Purified horseshoe crab factor G. Reconstitution and characterization of the $(1 \rightarrow$ 3)-beta-D-glucan-sensitive serine protease cascade. J. Biol. Chem. 270, 892-897.

Nagai, T. and Kawabata, S. (2000) A link between blood coagulation and prophenoloxidase activation in arthropod host defense. $J$. Biol. Chem. 275, 29264-29267.

Nagai, T., Osaki, T. and Kawabata, S. (2001) Functional conversion of hemocyanin to phenoloxidase by horseshoe crab antimicrobial peptides. J. Biol. Chem. 276, 27166-27170.

Nakajima, Y., Alvarez-Bravo, J., Cho, J., Homma, K., Kanegasaki, S. and Natori, S. (1997) Chemotherapeutic activity of synthetic antimicrobial peptides: correlation between chemotherapeutic activity and neutrophil-activating activity. FEBS Lett. 415, 6466.

Natori. S., Shiraishi, H., Hori, S. and Kobayashi, A. (1999) The roles of Sarcophaga defense molecules in immunity and metamorphosis. Dev. Comp. Immunol. 23, 317-328.

Nellaiappan, K. and Sugumaran, M. (1996) On the presence of phenoloxidase in the hemolymph of the horseshoe crab, limulus. Comp. Biochem. Physiol. 113, 163-168. 
Nonaka, M. (2001) Evolution of the complement system. Curr. Opin. Immunol. 13, 69-73.

Nonaka, M. and Azumi, K. (1999) Opsonic complement system of the solitary ascidian, Halocynthia roretzi. Dev. Comp. Immunol. 23, 421-427.

Nonaka, M., Azumi, K., Xin, J., Namikawa-Yamada, C., Sasaki, M., Saiga, H., Dodds, A. W., Sekine, H., Homma, M. K., Matsushita, M., Endo, Y. and Fujita, T. (1999) Opsonic complement component $\mathrm{C} 3$ in the solitary ascidian, Halocynthia roretzi. J. Immunol. 162, 387-391.

Nonaka, M. and Yoshizaki, F. (2004) Primitive complement system of invertebrates. Immunol. Rev. 198, 203-215.

Obayashi, T., Tamura, H., Tanaka, S., Ohki, M., Takahashi, M., Arai, M., Matsuda, M. and Kawai, T. (1985) A new chromogenic endotoxin-specific assay using recombined Limulus coagulation enzyme and its clinical application. Clin. Chim. Acta. 149, 55-65.

Ochiai, M. and Ashida, M. (1988) Purification of a beta-1,3glucan recognition protein in the prophenoloxidase activating system from hemolymph of the silkworm, Bombyx mori. J. Biol. Chem. 263, 12056-12062.

Ohno, S. (1994) MHC evolution and development of a recognition system. Ann. N. Y. Acad. Sci. 712, 13-19.

Okino, N., Kawabata, S., Saito, T., Hirata, M., Takagi, T. and Iwanaga, S. (1995) Purification, characterization, and cDNA cloning of a 27-kDa lectin (L10) from horseshoe crab hemocytes. J. Biol. Chem. 270, 31008-31015.

Osaki, T. and Kawabata, S. (2004) Structure and function of coagulogen, a clottable protein in horseshoe crabs. CMLS, Cell Mol. Life Sci. 61, 1257-1265.

Osaki, T., Okino, N., Tokunaga, F., Iwanaga, S. and Kawabata, S. (2002) Proline-rich cell surface antigens of horseshoe crab hemocytes are substrates for protein cross-linking with a clotting protein coagulin. J. Biol. Chem. 277, 40084-40090.

Osaki, T., Omotezako, M., Nagayama, R., Hirata, M., Iwanaga, S., Kasahara, J., Hattori, J., Ito, I., Sugiyama, H. and Kawabata, S. (1999) Horseshoe crab hemocyte-derived antimicrobial polypeptides, tachystatins, with sequence similarity to spider neurotoxins. J. Biol. Chem. 274, 26172-26178.

Pålsson-Mcdermott, E. M. and Onell, L. J. (2004) Signal transduction by the lipopolysaccharide receptor, Toll-like receptor-4. Immunol. 113, 153-162.

Pieters, J. (2001) Evasion of host cell defense mechanisms by pathogenic bacteria. Curr. Opin. Immunol. 13, 37-44.

Saito, T., Hatada, M., Iwanaga, S. and Kawabata, S. (1997) A newly identified horseshoe crab lectin with binding specificity to $O$-antigen of bacterial lipopolysaccharides. J. Biol. Chem. 272, 30703-30708.

Saito,T., Kawabata, S., Hirata, M. and Iwanaga, S. (1995) A novel type of limulus lectin-L6. Purification, primary structure, and antibacterial activity. J. Biol. Chem. 270, 14493-14499.

Salzet, M. (2001) Vertebrate innate immunity resembles a mosaic of invertebrate immune responses. Trends Immunol. 22, 285288.

Smith, L. C. (1999) The complement system in sea urchins. $A d v$. Exp. Med. Biol. 484, 363-372.

Smith, V. J. and Chisholm, J. R. (2001) Antimicrobial proteins in crustaceans. Adv. Exp. Med. Biol. 484, 95-112.

Smith, L. C., Azumi, K. and Nonaka, M. (1999) Complement systems in invertebrate. The ancient alternative and lectin pathways. Immunopharmacology 42, 107-120.
Söderhäll, K., Bangyeekhun, E., Mayo, S. and Söderhäll, K. (2003) Hemocyte production and maturation in an invertebrate animal: proliferation and gene expression in hematopoietic stem cells of Pacifastacus leniusculus. Dev. Comp. Immunol. 27, 661-672.

Söderhäll, K., Corenius, L. and Johansson, M. (1996) The prophenoloxidase activating system in invertebrates; in New Directions in Invertebrate Immunology, Söderhäll, K., Iwanaga, S. and Vasta, G. R. (eds.), pp. 229-254, SOS Publication, Fair Haven, USA.

Söderhäll, K., Johnasson, M. and Cerenius, L. (1994) Pattern recognition in invertebrates: The $\beta-1,3$-glucan binding proteins; in Phylogenetic Perspectives in Immunity: The Insect Host Defense, Hoffmann, J. A., Janeway, C. A. and Natori, S. (eds.), pp. 97-104, R. G. Landes Co., Austin, USA.

Suetake, T., Tsuda, S., Kawabata, S., Miura, K., Iwanaga, S., Hikichi, K. Nitta, K. and Kawano, K. (2000) Chitin-binding proteins in invertebrates and plants comprise a common chitinbinding structural motif. J. Biol. Chem. 275, 17929-17932.

Sugumaran, M. (2002) Comparative biochemistry of eumelanogenesis and the protective roles of phenoloxidase and melanin in insects. Pigment Cell Res. 15, 2-9.

Takahashi, H., Azumi, K. and Yokosawa, H. (1995) A novel membrane glycoprotein involved in ascidian hemocyte aggregation and phagocytosis. Eur. J. Biochem. 233, 778-783.

Takaki, Y., Seki, N., Kawabata, S., Iwanaga, S. and Muta, T. (2002) Duplicated binding sites for $(1 \rightarrow 3)$-beta-D-glucan in the horseshoe crab coagulation factor G: Implications for a molecular basis of the pattern recognition in innate immunity. J. Biol. Chem. 277, 14281-14287.

Tamura, H., Tanaka, S., Oda, T., Uemura, Y., Aketagawa, J. and Hashimoto, Y. (1996) Purification and characterization of a (1$3)-\beta-D-g l u c a n$ binding protein from horseshoe crab (Tachypleus tridentatus) amoebocytes. Carbohyd. Res. 295, 103-116.

Tan, N. S., Ho, B. and Ding, J. L. (2000) High-affinity LPS binding domain(s) in recombinant factor $\mathrm{C}$ of a horseshoe crab neutralizes LPS-induced lethality. FASEB $J$. 14, 859-870.

Tan, N. S., Ng, M. L., Yau, Y. H., Chong, P. K., Ho, B. and Ding, J. L. (2000) Definition of endotoxin binding sites in horseshoe crab factor $C$ recombinant sushi proteins and neutralization of endotoxin by sushi peptides. FASEB J. 14, 1801-1813.

Tanaka, S. and Iwanaga, S. (1993) Limulus test for detecting bacterial endotoxins. Methods Enzymol. 223, 358-364.

Theopold, U., Li, D. Schefer, C. and Schmidt, O. (2002) The coagulation of insect hemolymph. CMLS Cell. Mol. Life Sci. 59, 363-372.

Theopold, U., Schmidt, O., Söderhäll, K. and Dushay, M. S. (2004) Coagulation in arthropods: defense, wound closure and healing. Trends Immunol. 25, 289-294.

Tokunaga, F. and Iwanaga, S. (1993) Horseshoe crab transglutaminase. Methods Enzymol. 223, 378-388.

Tzou, P., De Gregorio, E. and Lemaitre, B. (2002) How Drosophila combats microbial infection: a model to study innate immunity and host-pathogen interactions. Curr. Opin. Microbiol. 5, 102-110.

Underhill, D. M. and Orinsky, A. (2002) Toll-like receptors: key mediators of microbe detection. Curr. Opin. Immunol. 14, 103110.

Vasta, G. R., Quesenbery, M. S., Ahmed, H, and O'Leary, N. (1999) Lectins from tunicates: Structure-function relationships 
in innate immunity. Adv. Exp. Med. Biol. 484, 275-287.

Wang, R., Lee, S. Y., Cerenius, L. and Söderhäll, K. (2001) Properties of the prophenoloxidase activating enzyme of the freshwater crayfish, Pacifastacus leniusculus. Eur. J. Biochem. 268, 895-902.

Waterfield, N. R., Wren, B. W. and Ffrench-Constant, R. H. (2004) Invertebrates as a source of emerging human pathogens. Nat. Rev. Microbiol. 2, 833-841.

Xin, J. I., Azumi, K., Sasaki, M. and Nonaka, M. (1997) Ancient origin of the complement lectin pathway revealed by molecular cloning of mannan binding protein-associated serine protease from a urochordate, the Japanese ascidian, Halocynthia roretzi. Proc. Natl. Acad. Sci. USA 94, 6340-6345.

Yoshida, H., Kinoshita, K. and Ashida, M. (1996) Purification of a peptidoglycan recognition protein from hemolymph of the silkworm, Bombyx mori. J. Biol. Chem. 271, 13854-13860.

Yu, X. Q., Gan, H. and Kanost, M. R. (1999) Immulectin, an inducible C-type lectin from an insect, Manduca sexta, stimulates activation of plasma prophenoloxidase. Insect Biochem. Mol. Biol. 29, 585-597.

Zhang, R., Cho, H. Y., Kim, H. S., Ma, Y. G., Osaki, T., Kawabata, S., Soderhall, K. and Lee, B. L. (2003) Characterization and properties of a 1,3-beta-D-glucan pattern recognition protein of Tenebrio molitor larvae that is specifically degraded by serine protease during prophenoloxidase activation. J. Biol. Chem. 278, 42072-42079.

Zhu, Y., Thangamani, S., Ho, B. and Ding, J. L. (2005) The ancient origin of the complement system. EMBO J. 24, 383394. 